NBER WORKING PAPER SERIES

\title{
DISCRIMINATION AS A SELF-FULFILLING PROPHECY: EVIDENCE FROM FRENCH GROCERY STORES
}

\author{
Dylan Glover \\ Amanda Pallais \\ William Pariente \\ Working Paper 22786 \\ http://www.nber.org/papers/w22786 \\ NATIONAL BUREAU OF ECONOMIC RESEARCH \\ 1050 Massachusetts Avenue \\ Cambridge, MA 02138 \\ October 2016
}

We would like to thank Yann Algan, David Autor, Thomas Le Barbanchon, Eric Cediey, Raj Chetty, Bruno Crépon, Muriel Dejemeppe, Eleanor Dillon, Esther Duflo, Erin Fletcher, Roland Fryer, Ed Glaeser, Lisa Kahn, Lawrence Katz, Danielle Li, Florian Mayneris, four anonymous referees, and seminar participants at Berkeley Haas, London School of Economics, Nova Business School of Economics, Paris School of Economics, Sciences Po, University of California Santa Barbara, University of Illinios at Urbana-Champaign, University of Namur, and UC Louvain for their helpful comments. We would also like to thank Lisa Abraham, Jenna Anders, Frédéric Cochinard, Elizabeth Mishkin, and Adrien Pawlik for superb research assistance. We gratefully acknowledge funding from the Fonds d'Expérimentation pour la Jeunesse (France). The views expressed herein are those of the authors and do not necessarily reflect the views of the National Bureau of Economic Research.

NBER working papers are circulated for discussion and comment purposes. They have not been peer-reviewed or been subject to the review by the NBER Board of Directors that accompanies official NBER publications.

(C) 2016 by Dylan Glover, Amanda Pallais, and William Pariente. All rights reserved. Short sections of text, not to exceed two paragraphs, may be quoted without explicit permission provided that full credit, including (C) notice, is given to the source. 
Discrimination as a Self-Fulfilling Prophecy: Evidence from French Grocery Stores

Dylan Glover, Amanda Pallais, and William Pariente

NBER Working Paper No. 22786

October 2016

JEL No. J24,J71,J78,M50

\begin{abstract}
Examining the performance of cashiers in a French grocery store chain, we find that manager bias negatively affects minority job performance. In the stores studied, cashiers work with different managers on different days and their schedules are determined quasi-randomly. When minority cashiers, but not majority cashiers, are scheduled to work with managers who are biased (as determined by an Implicit Association Test), they are absent more often, spend less time at work, scan items more slowly, and take more time between customers. Manager bias has consequences for the average performance of minority workers: while on average minority and majority workers perform equivalently, on days where managers are unbiased, minorities perform significantly better than do majority workers. This appears to be because biased managers interact less with minorities, leading minorities to exert less effort.

Dylan Glover

Sciences Po

28 rue des Saints-Pères

75007 Paris

dylan.glover@sciencespo.fr

Amanda Pallais

Department of Economics

Harvard University Littauer

Center Cambridge, MA

02138 and NBER

apallais@fas.harvard.edu

William Pariente

Institut de Recherche Économique et Sociale (IRES)

Universite Catholique de Louvain

Place Montesquieu 3, B-1348

Louvain-la-Neuve, Belgium

william.pariente@uclouvain.be
\end{abstract}




\section{Introduction}

A vast economic literature tests for the presence of labor market discrimination, a setting in which equally-productive minority and non-minority workers are treated differently in terms of hiring, pay, or promotion. Becker's pioneering work, The Economics of Discrimination (1957), introduced the notion of taste-based discrimination: employers experience disutility when employing minority workers and compensate by paying minorities less or requiring them to be more productive for the same wage. A subsequent body of work, starting with Phelps (1972) and Arrow (1973), conceived of discrimination not as a matter of animus but one of imperfect information. Unfavorable priors about minority workers' productivity or imperfect screening precision causes employers to treat equally-skilled minority and majority workers unequally. Building on these insights, Lundberg and Startz (1983) and Coate and Loury (1993) showed how statistical discrimination could potentially depress minorities' skill investments by leading minorities to correctly believe that these investments would not be fully rewarded. As a result, statistical discrimination may lead to a self-fulfilling prophecy whereby employers' adverse prior beliefs about minorities' skill levels are self-confirming in equilibrium.

Something that unites these strands of literature is the implicit assumption that employers' tastes and beliefs do not directly impact worker productivity. Although statistical discrimination might inhibit skill investment, it does not directly affect the performance of workers with given skill levels. However, a strand of literature beginning with Steele and Aronson (1995) documents that adverse stereotypes about minority groups' abilities can directly reduce group members' performance. This body of work demonstrates that when stereotypes are made salient prior to performance (e.g., test-takers are asked to report their race or gender), blacks, Hispanics, and women tend to perform significantly worse than in settings where group membership is not made salient. This line of research, which has so far had limited influence on the economic literature, implies that adverse employer beliefs about minorities - whether stemming from animus or statistical discrimination - could be self-fulfilling, not because they inhibit minority skill investment but because they induce minorities to perform worse on the job. Related research shows that individuals' own stereotypes can negatively impact their performance (Coffman, 2014) and that these stereotypes need not be fully accurate (Bordalo et al., forthcoming).

This paper presents a novel test of whether discriminatory beliefs directly affect minority workers' job performance in a real-world workplace. ${ }^{1}$ We study 34 outlets of a French grocery

\footnotetext{
${ }^{1}$ This is related to the literature showing that workers and students benefit from interacting with coethnics. See, e.g., Dee (2004) and (2005), Stoll et al. (2004), Stauffer and Buckley (2005), Giuliano et al. (2009) and (2011), Price and Wolfers (2010), and Hjort (2014). This is also related to the literature
} 
store chain. In these stores, there is a sizable proportion of minority workers that, based on their names, we identify as having a North African or Sub-Saharan African origin. ${ }^{2}$ We study new cashiers hired on six-month contracts since these workers are assigned quasi-randomly to managers. These cashiers, like all cashiers in the stores, work with different managers on different days. Unlike more senior workers, however, they are not allowed to submit schedule preferences. Their schedules are determined by a computer program which assigns shifts to meet predicted demand, taking into account the preferences of more senior workers. This ensures that the minority and majority workers in our sample do not choose the managers they work with and that minority and non-minority workers work with the same managers under similar conditions. Worker and manager schedules are publicly posted several weeks in advance, so workers know which managers they will be working with beforehand.

We measured managers' bias towards minorities with an Implicit Association Test (IAT). This test is widely used to measure bias, particularly in psychology (see Nosek et al., 2007; Lane et al., 2007; and Greenwald et al., 2009 for summaries of the literature). IAT scores have been correlated with many real-world decisions and are difficult for subjects to manipulate. ${ }^{3}$ The test uses the speed with which subjects categorize prompts to determine the implicit association that individuals have between two concepts: here (1) traditionally French or North African sounding names and (2) words indicating worker competence or incompetence. Our manager bias score thus measures the extent to which managers associate North African names with poor worker performance. This concept is correlated with, but distinct from, managers' distaste for minorities (Agerstrom et al., 2007).

Each of the stores in our sample tracks individual performance at a daily level. The stores provided us with data on absences and time worked (determined by time clock data), scanning speed, and time taken between customers. Absences are particularly important to the firm and being absent three times is one of the few ways a worker can be fired during her initial six-month contract. The firm also particularly cares about scanning speed. It posts a list of workers' articles scanned per minute in the break room each week. The firm uses these performance metrics and consultations with the managers about workers' performance and customer relations to determine whether workers will be offered a longer contract at the end of their six-month contract. Approximately 30-40\% of workers are offered a longer contract.

started by Rosenthal and Jacobson (1968) showing that teachers' expectations about student performance can directly affect student outcomes.

${ }^{2}$ Workers are categorized into minority and non-minority status based on their names because in France it is illegal to ask workers their ethnicity. ISM CORUM, an expert in discrimination testing in France, did the categorization. We gave ISM CORUM separate lists of first and last names, so that it would not be able to identify any individual in the study.

${ }^{3}$ See e.g., Kim (2003), Friese et al. (2007), Green et al. (2007), Greenwald et al. (2009), and Rooth (2010). 
We assess whether minority cashiers perform worse on the days they work with managers who are biased against their minority group. Because there may be other differences between more- and less-biased managers - biased managers may simply be less skilled, for example - we do not want to simply attribute the change in minority performance when working with more-biased managers to manager bias. Instead, we utilize a difference-in-difference methodology, comparing the change in minority workers' performance under more- and lessbiased managers to the change in non-minority performance.

We find that manager bias leads minorities to perform worse. When scheduled to work with biased managers, minorities are more likely to be absent. When they do come to work, they spend less time at the store. This is driven by the fact that they are much less likely to stay after their scheduled shift ends. While workers are allowed to leave when their shift ends, managers can ask them to work late. Because workers are paid based on time worked, we estimate that minorities earn $2.5 \%$ less as a result of manager bias.

Minorities also scan items more slowly and take more time between customers when working with biased managers. Throughout our analyses, none of the differential effects of working with more-biased managers are explained by the other manager characteristics we have, including the managers' own minority status. The effect of manager bias is concentrated in stores with fewer minority workers and appears to grow during the contract (though this latter difference is not statistically significant).

We use data from a worker survey conducted after the contract to distinguish between theories of discrimination that can explain our results. ${ }^{4}$ First, we find little evidence that animus - or biased managers treating minorities poorly - can explain our results. Minority workers do not report that biased managers disliked them or that they disliked biased managers. They report that biased managers were less likely to assign them to unpleasant tasks (cleaning) and no more likely to assign them unpleasant registers or breaks.

Our evidence is most consistent with a theory in which biased managers interact less with minority workers. Research in psychology on "aversive racism" has found that individuals with implicit biases towards minority groups are less likely to speak to, more hesitant in speaking to, and less friendly towards members of those groups. ${ }^{5}$ They may feel less comfortable interacting with minorities or they may be concerned about appearing biased. Using whether a worker remembered each manager as an indicator for worker-manager in-

\footnotetext{
${ }^{4}$ One explanation that cannot drive the day-to-day differences in performance we find is that biased managers depress minority human capital accumulation. Minorities may accumulate fewer skills under biased managers, but we would not detect this since minorities would have any skills they learned working with unbiased managers on the days when they work with biased managers.

${ }^{5}$ See, e.g., McConnell and Leibold (2001), Dovidio et al. (2002) and Hebl et al. (2002). Dovidio and Gaertner (2008) summarize this literature.
} 
teraction, we find minorities were less likely to remember biased managers. Worker-manager interaction appears to be a key determinant of performance: workers performed substantially better when working with managers they remembered. ${ }^{6}$ Biased managers interacting less with minorities is consistent with the fact that biased managers were less likely to ask minorities to do cleaning duties. It may also explain why minorities are less likely to stay after the end of their shifts when working with biased managers: the managers may simply not ask them to.

An alternative explanation concerns stereotypes. Minorities may hold negative stereotypes about their suitability for the job or be aware of existing stereotypes about their group and biased managers may activate these negative stereotypes. To test whether this occurred, we asked workers which managers gave them the most confidence in their abilities. Minorities do not report that biased managers gave them less confidence in their abilities. Nevertheless, this does not rule out an explanation whereby biased managers subconsciously activate minorities' negative stereotypes.

Finally, we test whether the negative impact of manager bias on minority performance leads to statistical discrimination in hiring. If it did, the store would act as if minority workers were less productive than majority workers with the same characteristics. In the absence of manager bias, hired minorities would actually be more productive than hired majority workers. Overall, we find that minority and majority workers perform equivalently. There is no difference in their average absence rates, time spent at work, articles scanned per minute, or time taken between customers. However, consistent with statistical discrimination, when working with unbiased managers, minority workers perform substantially better than do non-minorities. They are half as likely to be absent and scan significantly faster.

With some assumptions, we can combine our performance metrics to estimate the number of customers each worker serves per day. On average, minorities serve an insignificant $2 \%$ more customers than do majorities. However, on days with unbiased managers, minorities serve $9 \%$ more customers than majorities do. This is a substantial difference: while the average minority is at the 53rd percentile of average worker performance, on days with unbiased managers she is at the 79th percentile. This suggests there are real consequences of manager bias on minority workers' performance and thus, in theory, workers' subsequent labor market outcomes. ${ }^{7}$

\footnotetext{
${ }^{6}$ This is consistent with Mas and Moretti (2009) which finds that monitoring improves cashiers' performance.

${ }^{7}$ Unfortunately, we do not have data on which workers were offered a second contract. Our identification strategy also does not lend itself well to determining the effect of manager bias on workers' subsequent labor market outcomes since over the six-month contract, there is little variation in the average bias workers are exposed to.
} 
The paper proceeds as follows. Section 2 explains the empirical context, while Section 3 discusses the theories of discrimination that could explain our results and their testable predictions. Section 4 describes the data, provides descriptive statistics, and tests the identifying assumption that minority and majority cashiers work with more- and less-biased managers under similar conditions. Section 5 presents the main results of the paper, showing that across several outcomes, minorities perform worse when working with more-biased managers. Section 6 tests the predictions of the different theories of discrimination and Section 7 concludes.

\section{Setting}

We study entry-level cashiers in a large French grocery store chain. These cashiers are hired on a specific contract called Contrat de Professionnalisation (CP): a six-month contract subsidized by the government. In return for the subsidy, the firm trains CP workers on being a cashier and the retail sector in general. Apart from the direct subsidy, these contracts are advantageous to firms because they include a week-long trial period before the official contract start date in which workers are trained without pay. During this week, either party can walk away from the contract without penalty.

$\mathrm{CP}$ cashiers complete the same job (running a cash register) as other workers. However, there are two special aspects of their employment. First, one day each week CPs attend training, during which they are not on the store floor. (Training days are not included in our data.) Second, CPs have no control over their schedules. All other cashiers are allowed to submit schedule preferences. A computer system assigns shifts by matching predicted demand to the available workforce, taking the preferences of non-CP workers into account. The computer system is constrained to ensure that workers have the requisite number of days off and that no worker may have more than two split shifts per week, open the store more than twice per week, or close the store more than twice per week. ${ }^{8}$ Schedules are determined three weeks at a time and, once determined, publicly posted. Manager schedules are also publicly posted in advance, so workers know ahead of time which managers they will be working with. The chief cashier (the managers' boss) can, in theory, revise the schedules assigned by the computer system. However, this happens very rarely.

The stores typically have around five cashier managers (henceforth managers) and 100 to 250 cashiers. There are 30 to 80 registers in each store, though it is rare that all the registers are open at once. The manager on duty sits in a special station in the middle of

\footnotetext{
${ }^{8} \mathrm{~A}$ split shift occurs when a worker is scheduled to work for two separate periods in the same day (e.g., from 9 am to $12 \mathrm{pm}$ and from $3 \mathrm{pm}$ to $6 \mathrm{pm}$ ).
} 
the registers. When a cashier arrives for her shift, she badges (clocks) in near the manager station. She typically has a brief conversation with the manager, who gives her the day's news and assigns her to a register. Some workers are assigned to special cash registers, such as the 10 items or less line or the self-checkout, though this is rare for CPs. The worker then gets her till (cash box) from the safe, sets it up at her station, and starts receiving customers. There are no baggers in these stores; customers bag their items themselves.

The manager roams the store, talking with cashiers and monitoring them at their stations. She manages the lines, opening and closing new ones and directing customers to short ones. Cashiers whose lines are closed are assigned to other tasks such as aisle arrangement, the welcome desk, or assisting managers. The manager also decides when workers can go on break, though the amount of break time is specified in workers' contracts. Workers are allowed to leave at the end of their shifts, but the manager can ask them to work late. Before leaving, cashiers confer with the manager, return their till to the safe, and badge out near the manager station.

CP workers are hired in waves: approximately twice a year each store has a "promotion," in which new CPs are hired. The managers we study are rarely involved in the hiring process, which is conducted by the chain's central office and the store's chief cashier.

The most important performance metrics for workers are showing up to work, showing up on time, and having the correct amount of money in the till. During the CP, workers can only be fired for misconduct, which includes having more than three absences, being late more than three times, having more than three warnings for misbehavior, or having even one report of violent conduct or one large till deviation. If misconduct occurs, the chief cashier decides whether to fire the $\mathrm{CP}$, relying on the advice of the managers. Aside from misconduct, the most important indicator of cashier performance is the number of articles scanned per minute. Each week, a list of workers' average articles per minute is publicly posted in the employee break room.

CPs are not paid based on performance; they are paid solely based on time worked. In particular, CPs are not paid for days they are absent, though after three sick days and a doctor's authorization, the government pays $70 \%$ of workers' pay during their sick leave. ${ }^{9}$ CPs' paychecks are also adjusted if they work more or less than scheduled.

CPs' main incentive to perform well is the opportunity to receive another contract. After their initial CP, about $30 \%$ to $40 \%$ of workers are offered another contract. The chief cashier decides whether to offer subsequent contracts to each worker based on the worker's performance, manager evaluations, and the number of available positions at the store. These

\footnotetext{
${ }^{9} \mathrm{CPs}$ earn vacation time, but cannot use it for days off: they are paid for their vacation days after the end of the contract.
} 
subsequent contracts are of longer duration and pay higher salaries.

Managers are on indefinite-term contracts with fixed pay, not dependent on their performance. However, they undergo a yearly performance review with the chief cashier which assesses customers' checkout experience. This is in large part determined by how quickly the lines move, though it also includes register cleanliness, the stocking of the small shelves at each register, and effectively handling customer problems. While managers are graded on their support of inexperienced cashiers, they do not have the primary responsibility for cashier training.

\section{Theories of Discrimination}

We discuss several theories of discrimination and the predictions they make for our context. We discuss only those theories that could explain our main results: that minorities are absent more often, leave work earlier, and have worse on-the-job performance on days when they work with more-biased managers. For example, while manager bias may impede minority skill development (e.g., Lundberg and Startz, 1983; Coate and Loury, 1993), our study cannot assess whether this occurs. Even if it did, minorities would have similar skills on days when they worked with both more- and less-biased managers.

The first four columns of Table 1 summarize the predictions of these theories, which are tested in Section 6.

\section{Beckerian Taste for Discrimination}

Biased managers may simply dislike minorities. This animus could lead biased managers to treat minorities badly and give them unpleasant tasks. This may make minorities dislike coming to work, so they are absent more often and leave work earlier. This animus could also impede minority performance on the job. To test whether manager animus drives our results, we assess whether minorities report that biased managers liked them less and assigned them to unpleasant tasks in a worker survey conducted after the end of the contract.

\section{Less Interaction and Statistical Discrimination}

Individuals with higher implicit biases towards a minority group have been found to spend less time talking to, to have more hesitation in speaking to, and to act less friendly towards minority group members (McConnell and Leibold, 2001; Dovidio et al., 2002; and Hebl et al., 2002). Biased individuals may be uncomfortable interacting with minorities or their actions can be driven by a desire to seem unprejudiced (see Dovidio and Gaertner, 2008 for a summary of the literature on aversive racism). In our context, this may lead biased managers to spend less time at the stations of minority workers. When they need a task accomplished - even an unpleasant one - they may be less likely to ask a minority. 
Minorities may realize which managers are paying less attention to them and exert less effort when these managers are on duty.

These lower minority effort and performance levels can lead to statistical discrimination in hiring (Phelps, 1972; Arrow, 1973). Statistical discrimination leads the firm to act as if minority workers are less productive than majority workers with the same qualifications. Under statistical discrimination, hired minorities would have better qualifications than hired majority workers and they would be more productive than majorities when not exposed to manager bias.

We use the worker survey to test whether biased managers interact less with minority workers and are less likely to assign minorities to unpleasant tasks. We test for statistical discrimination by assessing whether minorities perform better than majority workers on days with unbiased managers.

Stereotypes and Statistical Discrimination

Stereotypes could also lead minorities to perform worse under biased managers. Under self-stereotyping (Coffman, 2014), workers' expectations about their group's suitability for a given task affect their performance. Here, minorities might think that workplace environments (even relatively low-skill ones) are not environments where minorities thrive. For self-stereotyping to lead to different performance on different days, workers would have to either update their stereotypes from day to day or these stereotypes would have to be differentially activated by certain managers. A closely-related explanation is stereotype threat (Steele and Aronson, 1995), under which the risk of confirming negative group stereotypes leads minorities to become anxious and perform worse. To assess the extent to which managers differentially activate either self-stereotypes or stereotype threat, we asked workers the extent to which different managers made them feel confident in their abilities. While

this tests for conscious activation of stereotypes, it would not capture stereotypes activated subconsciously.

Worse minority performance due to stereotypes could also lead to statistical discrimination in hiring. As above, we test for this by comparing minority and majority performance on days with unbiased managers.

\section{Data and Descriptive Statistics}

\subsection{Data Sources}

We utilize three sources of data: store administrative data, manager survey data, and worker survey data. The store administrative data provide information on worker and manager 
schedules and worker performance. The manager survey data provide our measure of manager bias. We use the worker survey data to learn about the mechanism for the effect.

\subsubsection{Administrative Store Data}

We collected daily data for each CP in a given promotion over a six-week period between July 2011 and August 2012. We have schedule data: the precise times at which workers and managers were supposed to begin and end their shifts. These data allow us to determine which manager(s) a worker was scheduled to work with on a given day.

We also have badge data: the precise times that workers and managers badged in and out of the stores. Both managers and CPs must badge in and out at the beginning and end of their shifts and for breaks, so we have actual working times to the minute. Combining these data with the schedule data provides our first two metrics of worker performance: absence and the number of minutes worked relative to the number of minutes the worker was scheduled to work. ${ }^{10}$ Time spent at the store can differ from what was scheduled for three reasons: (1) workers arrive earlier or later than scheduled, (2) workers leave earlier or later than scheduled, and (3) workers take breaks. While workers are entitled to breaks, these are not scheduled by the computer program.

We also have daily worker performance data, most importantly, articles per minute scanned. The time over which articles per minute is calculated starts when a worker scans a customer's first item and stops when a worker scans a customer's last item, so it is not affected by the time between customers. We also have two other determinants of line speed. The first is inter-customer time: the time between finishing one customer's transaction and starting to scan the next customer's items. The second is payment time: the time between the scanning of a customer's last item and the completion of the customer's transaction, during which time she is paying. While the firm tracks both of these metrics, they are not emphasized as key measures of performance by the firm.

Our final sample has 34 stores, including 204 workers and 4,371 worker-day observations. ${ }^{11}$ We initially asked for data from all of the chain's stores in France and received the necessary administrative data from 45 of them. From these 45 stores, we eliminate 11 in which managers did not take the IAT. (The process of getting managers to take the IAT is explained more below.) Because most stores had multiple promotions during the year, we have data on 51 promotions from the 34 stores in our sample. Two stores did not provide

\footnotetext{
${ }^{10}$ We analyze time worked relative to time scheduled instead of simply time worked to gain precision.

${ }^{11}$ Throughout the paper, we cluster standard errors at the store level to allow for correlation in performance both within and across days in a store. While we have more than 30 clusters, we show that p-values are similar when we use a wild cluster bootstrap procedure that is robust to having a small number of clusters (Cameron et al., 2008, Garthwaite et al., 2014).
} 
data on inter-customer time, while four did not provide data on payment time, so we have slightly smaller samples for these outcomes. ${ }^{12}$

Because we wanted variation in the timing of the observations during the contract, we asked for data on weeks three through eight of the contract for some promotions and weeks 18 to 23 for others. Because stores kept data for one year only, we have data on weeks 18 to 23 for promotions that occurred chronologically earlier and data on weeks three to eight for promotions that occurred chronologically later.

In addition to these data, the stores provided a few other worker and manager characteristics. Most importantly, it provided their names. In France, it is illegal to ask people about their ethnicity. Thus, we utilize workers' names as an indicator of their minority status. ISM CORUM (Inter Service Migrants, Centre d'Observation et de Recherche sur L'Urbain et ses Mutations), a leading specialist in discrimination testing in France, performed the categorization. We provided ISM CORUM with separate lists of first and last names, so that it did not know the name of any individual in our study, much less any information about the workers it classified. Each first and last name was categorized into one of five possible origin types: (1) European, (2) North African, (3) Sub-Saharan African, (4) Mixed or undetermined, and (5) Other (including names of Turkish and Asian origins). We consider workers with a North African and Sub-Saharan sounding first or last name as the minorities in this context. In the appendix we show results are robust to using other definitions of minority status.

We also classified workers' and managers' gender using their names. The chain also provided managers' rank (position) within the store and managers' date of birth.

\subsubsection{Manager Survey and IAT}

We measure managers' bias towards minority workers using an Implicit Association Test (Greenwald et al., 1998; Nosek et al., 2007). The IAT is widely used, particularly in psychology, to measure unconscious bias. The test involves categorizing two sets of words to the left- and right-hand sides of a computer screen. In our case, subjects were presented with (1) names typically indicating a French origin (e.g., Jean) or names traditionally indicating a North African origin (e.g., Ahmed) and (2) adjectives that describe good employees (e.g., reliable) or bad employees (e.g., incompetent).

In all rounds, one word at a time (either a name or adjective) comes onto the screen and subjects are told how to categorize it (e.g., adjectives describing good employees to the left,

\footnotetext{
${ }^{12}$ One store simply did not provide data on either of these outcomes. The remaining stores provided data on the total amount of inter-customer time or payment time during the worker's shift, not scaled by the number of customers served.
} 
adjectives describing bad employees to the right). Subjects are instructed to categorize the words as quickly as possible. In the rounds used for scoring, the names and the adjectives are interspersed. In one of these rounds, subjects are tasked with categorizing French sounding names and negative adjectives to the same side of the screen, while in the other, they are tasked with categorizing North African sounding names and negative adjectives to the same side. The idea behind the test is that if a subject has an implicit association between two concepts (e.g., workers of North African origin and bad employees), it should be easier and quicker to do the categorization when they are placing those words on the same side of the screen. The test produces a measure of bias that compares the time taken to categorize items when North African sounding names and negative adjectives are categorized on the same side of the screen, relative to when French sounding names and negative adjectives are categorized on the same side. ${ }^{13}$

IAT scores have been found to be correlated with judgments, choices, and psychological responses (Bertrand et al., 2005). For example, IAT scores are correlated with voting behavior (Friese et al., 2007), callback rates of minority job applicants (Rooth, 2010), and doctors' provision of differential medical treatments by race (Green et al., 2007). Moreover, research suggests that it is very difficult to fake an IAT score. ${ }^{14}$

The chain's human resource office contacted the chief cashier in each store, asking them to get the managers to take the IAT as part of a study. While managers could likely tell from the IAT that the study concerned their beliefs about minorities, they did not know the exact purpose of the study. Managers were allowed to take the test during work hours, but did not receive any payment for doing so. Initially, managers received an email with a link to the IAT so that they could take the IAT at their convenience. We sent email reminders and periodically called the chief cashiers to induce more managers to take the test. We also visited stores that had technical difficulty accessing the IAT website, administering the IAT in person to these managers.

The managers took the IAT on average 17 months after the administrative data in our sample. Thus, neither taking the IAT nor knowledge of our study could have affected managers' treatment of minority workers in our data. Managers' experience in the store could have affected their implicit beliefs, but it seems very unlikely that interaction with the CPs in our study would have led to variation in those beliefs. In particular, our identification strategy ensures that the more- and less-biased managers we compare worked with the same

\footnotetext{
${ }^{13}$ We randomized the order in which subjects completed these rounds. We also included practice rounds to mitigate order effects (Nosek et al., 2007). We used the computer software Inquisit to administer the IAT.

${ }^{14}$ See, e.g., Banse et al. (2001), Egloff and Schmukle (2002), Kim (2003), Greenwald et al. (2009), and Hu et al. (2012). Faking a score on an IAT requires a specific strategy of slightly speeding up or slowing down in certain blocks, a strategy that few participants spontaneously discover (Greenwald et al., 2009).
} 
CPs. The vast majority of our managers (85\%) had been at the store for over 10 years, so would have seen at least 20 different $\mathrm{CP}$ promotions, several more recent than the ones we study. In addition to the CPs, these managers have managed 100 to 250 workers at a time for many years (relative to an average of six CPs per manager in our study), most of whom they work with much longer than with CPs. Moreover, the effects do not change with the length of time between the administrative data and when managers took the IAT. Finally, we use male names in the IAT (over $90 \%$ of our CPs are female) so managers are not prompted by the names of specific workers.

While it is unlikely that interacting with the CPs in our study affected managers' IAT scores, interacting with minorities in general might have. For example, if minorities disliked some managers and, as a result, performed badly for them, these managers might have developed negative beliefs about minority workers' performance. We think this is unlikely: minorities do not report disliking biased managers and the negative impacts on minority performance appear to be driven by manager actions, not solely worker actions. Nevertheless, we cannot fully rule out this alternative explanation.

We have IAT scores for $77 \%$ of the managers in the 34 stores. On most dimensions we have, managers who took the IAT and those who did not look similar. Managers who took the IAT were the same average age and were equally likely to be a minority and to have a high position in the store as managers who did not. Calculating manager fixed effects for all of our performance outcomes produces no significant differences between managers who did and did not take the IAT. (These differences are also inconsistently signed.) There is no correlation between the number of days it took managers to take the IAT after we requested it and their IAT scores, so it does not necessarily appear that more-biased managers were more reluctant to take the test. Male managers were less likely than were female managers to take the IAT. We show, however, that our results are robust to including controls for manager gender and manager gender interacted with worker minority status.

\subsubsection{Worker Survey}

We conducted a telephone questionnaire from May 2013 to September 2013, surveying former CPs about their relationship with each of their managers. The heart of the questionnaire comprised CPs ranking their managers on a variety of dimensions. Respondents rated the extent to which they remembered each manager, which we use as a measure of worker-

manager interaction. We also described manager traits or actions (e.g., the manager who liked the worker best) and asked workers to rate in order the top and bottom three managers 
on each trait. ${ }^{15}$ We provided workers with a list of managers, but did not tell workers managers' IAT scores, nor did we ask whether they thought the managers were biased.

Half of surveyed workers responded. The main cause of non-response was that CPs no longer had the same contact information and their phone numbers had been disconnected. (Only 2\% of workers answered the phone but refused to answer the survey.) We have survey responses for 94 workers in our main sample. Because we did not know which stores would provide performance data when we conducted the survey, we surveyed a larger sample. We also have survey data for 74 workers for whom we have manager IAT but not performance data and 10 workers for whom we have performance data but not manager IAT scores.

Controlling for store fixed effects, minorities were 7.4 percentage points less likely to respond to the survey (off a base of $52.6 \%$ for majorities). While this is not a statistically significant difference, it is not a small one. Appendix Table 1 compares the characteristics and performance of workers who responded and workers who did not, for the whole sample and separately for minority and majority workers. There are few differences between respondents and non-respondents. Of the 30 comparisons in the table, one is significant at the $5 \%$ level and two are significant at the $10 \%$ level. ${ }^{16}$ This is consistent with chance differences.

\subsection{Descriptive Statistics}

Table 2 reports descriptive statistics. We only know two things about all CPs: their minority status and gender, both based on their names. While $28 \%$ of workers are minorities, only $7 \%$ are male. The CP survey paints a slightly richer picture of workers in these stores. Despite the fact that this is an entry-level job, the average worker is 30 years old and has had four previous jobs. This is the first job for only $11 \%$ of the sample. Most workers (61\%) do not have a high school degree, while relatively few (7\%) have more than a high school education.

Managers tend to be older: they average 41 years of age. Relatively few of the managers are minorities themselves (6\%) and few are male (10\%). Managers' IAT scores suggest that most are biased against minorities. For ease of interpretation, throughout the paper, we divide managers' raw IAT scores by the standard deviation (0.36) in our sample. Positive scores indicate preference for majorities while negative score indicate preference for minorities. The average (scaled) manager IAT score is thus 1.35, which means that the average manager is 1.35 standard deviations away from being completely unbiased. Using the typical

\footnotetext{
${ }^{15}$ Most workers had six or fewer managers during the CP. In a pilot, we asked workers to rate all of their managers. However, workers found this difficult. There was substantial non-response and a few workers asked to stop the survey.

${ }^{16}$ Respondents worked more minutes per day than did non-respondents both among majority workers and in the overall sample. Respondents in the overall sample were also less likely to be from the Paris region.
} 
thresholds in the literature, ${ }^{17} 9 \%$ of managers show little to no bias against minorities, $20 \%$ show a slight bias against minorities, and $66 \%$ of our sample shows moderate to severe bias against minorities. Only $4 \%$ of our sample shows a preference for minorities. These managers seem approximately as biased as US undergraduates are against African-Americans though more biased than Americans who choose to take an IAT online (e.g., Amodio and Devine, 2006; Smith-McLallen et al., 2006; Mooney, 2014).

Appendix Table 2 shows the results of regressing manager IAT score on manager characteristics. The point estimates suggest that older managers tend to be more biased, while minority managers are less biased against their own group. However, none of these coefficients are significant, partially because we have so few minority managers. ${ }^{18}$ Minority CPs work, on average, in stores where managers are just as biased as do majority CPs.

Workers are scheduled to work just over four days per week on average (in addition to the training day). Working days are distributed relatively evenly Monday through Saturday. We have relatively few observations on Sundays as the firm opens on Sundays only during December. Workers are scheduled to work just over seven hours per day on average. The median shift starts at 10:15 am and ends at 8:15 pm.

Table 2 also provides the means of the dependent variables. First, CPs are absent less than $2 \%$ of working days, an absence rate that leads to an average of two absences over the six-month contract. Second, CPs work almost exactly the number of minutes they are scheduled to. Workers badge out of the store during breaks, but they tend to arrive earlier and stay later than scheduled. On average, CPs scan approximately 18.5 articles per minute, take just under 30 seconds between finishing one customer's transaction and starting the next ${ }^{19}$ and spend approximately 50 seconds per customer in payment time.

\subsection{Exogeneity}

Throughout the paper we want to interpret any change in performance when minority workers worked with biased managers - relative to when majority workers worked with biased

\footnotetext{
${ }^{17}$ See, e.g., Greenwald et al. (2003), Rooth (2010), Haider et al. (2011), and Hahn et al. (2014). Raw IAT scores below -0.15 indicate some preference for minorities; scores between -0.15 and 0.15 indicate little to no bias; scores between 0.15 and 0.35 indicate a slight bias against minorities; and scores above 0.35 show moderate to severe bias against minorities.

${ }^{18}$ The coefficients suggest that, on average, minority managers are 0.44 standard deviations less biased and a manager 10 years older is 0.08 standard deviations more biased. Controlling for other manager characteristics and store fixed effects, these effects decrease to 0.14 and 0.03 standard deviations, respectively.

${ }^{19}$ We eliminate 25 observations where workers spent more than two minutes on average between customers throughout the day. We think these are likely data errors or they indicate that something else was going on in the store outside the CP's control. (For example, one observation indicates that a worker spent 49 minutes on average between customers.) Spending over two minutes on average between customers is unrelated to manager bias or the interaction of manager bias and worker minority status.
} 
managers - as a causal effect of working with those managers. The key assumption is that minority workers were not systematically scheduled to work with biased managers on days or times when their performance would have been particularly high or low for other reasons. We first assess whether minority and majority workers were scheduled to work at similar times under similar conditions. We then analyze whether minority and majority workers were scheduled to work with more- and less-biased managers at similar times under similar conditions. Throughout the paper, we use the times that CPs and managers were scheduled to work to construct CPs' exposure to bias since CPs' actual working times respond to the managers they are paired with.

Panel A of Table 3 compares the shifts minority and majority workers were scheduled to work. Each column in the panel presents a separate regression of a characteristic of a scheduled working day on an indicator for the worker's minority status. We control for store fixed effects, as shift assignment is only quasi-random within a store. We cluster standard errors at the store level.

The first dependent variable is the bias (IAT score) of the manager the CP was scheduled to work with. For workers who were scheduled to work with multiple managers on a given date, this is a weighted average of the managers' IAT scores, where the weights are the amount of time each worker was scheduled to work with each manager. If we do not have a manager's bias score, we simply omit this manager from the calculation. We might have expected that if minority workers had control over their schedules or their schedules were assigned non-randomly by managers, they would have been less likely to work with biased managers than were majority workers. Instead, we see that this difference is not significant and the point estimate goes in the opposite direction. The next column investigates whether minority workers are more likely to work with managers who themselves are minorities. Again, we find no effect. Next, we consider minorities' likelihood of working with male managers and Level 4 managers (who are higher in the store hierarchy than Level 3 managers). We see no difference in the likelihood that minority and majority workers are scheduled to work with different types of managers. Nor do we see a difference in the number of managers they work with on a shift (Column 5).

The next column considers the days worked. Workers may systematically scan articles faster on some days than others, for example because stores are busier. To construct a single measure of how productive workers are on a given date, we calculate the average articles scanned per minute in all other stores in our data (excluding the store itself) on that date. We see no evidence that minority workers work on particularly productive or unproductive days, nor are minority workers any more or less likely to work in the early morning or late evening. Minority and majority workers work the same number of hours per day and are 
equally likely to have split shifts. Appendix Table 3A shows that minority and majority workers also work under similar conditions when we do not restrict the sample to days in which they are working with at least one manager who took the IAT.

Table 3B assesses whether minority workers work with more- and less-biased managers under the same conditions as do non-minorities. It presents the results of estimating the equation

$$
y_{i s t}=\alpha+\beta_{1}\left(\text { minority }_{i} \times \text { bias }_{i s t}\right)+\beta_{2} \text { bias }_{i s t}+\beta_{3} \text { minority }_{i}+\delta_{s}+\varepsilon_{i s t} .
$$

Here, $y_{i s t}$ is a characteristic of the shift worker $i$ in store $s$ who was scheduled to work on day $t$. Minority $i$ is an indicator for worker $i$ being a minority and bias ist $_{\text {is }}$ the bias of the manager that the worker was scheduled to work with on day $t$ in store $s$, measured using managers' scaled IAT scores. Store fixed effects, $\delta_{s}$, are also included. The coefficient $\beta_{2}$ can be significantly different from zero without violating our key assumption, though it never is. This term measures how the conditions under which more- and less-biased managers work with non-minorities differ. The coefficient $\beta_{3}$ measures how the working conditions of minority and majority CPs differ when working with unbiased managers. We see across the board that these coefficients are insignificant. The coefficient on the interaction term, $\beta_{1}$, is the primary coefficient of interest. This coefficient shows how the working conditions of minority CPs change relative to the change in the working conditions of majority CPs when both work with a manager one standard deviation more biased. Again, all the coefficients are insignificant. Appendix Table 3B shows that the all the coefficients are also insignificant when we include worker fixed effects instead of store fixed effects. Appendix Table 4 shows that minority CPs are not differentially likely to be scheduled to work at the same times as other minority CPs.

\section{Effect of Manager Bias on Performance}

We now turn our attention to assessing whether minority workers perform worse when paired with biased managers. We first consider absence rates and the amount of time spent at work. These metrics are important to the firm and directly affect workers' pay. Then, we consider measures of performance while at work, the most important of which is articles scanned per minute.

To determine the effect of manager bias on worker performance, we estimate the equation

$$
y_{i s t}=\alpha+\beta_{1}\left(\text { minority }_{i} \times \text { bias }_{i s t}\right)+\beta_{2} \text { bias }_{i s t}+\delta_{i}+X_{i s t} \beta_{3}+\varepsilon_{i t} .
$$


Here, $y_{i s t}$ is a performance metric for worker $i$ in store $s$ on day $t$ (e.g., the number of articles per minute scanned). Minority M $_{i}$ and Bias $s_{i s t}$ are defined as in the previous section. The regression controls for worker fixed effects, $\delta_{i}$, and shift characteristics $X_{i s t}$. Standard errors are clustered at the store level. The coefficient of interest, $\beta_{1}$, measures how minorities' performance changes (relative to the change in non-minority performance) when working with a manager one standard deviation more biased.

We expect the estimate of $\beta_{1}$ to be attenuated due to measurement error. Workers' names do not provide a perfect measure of minority status and we do not have IAT scores for all managers. However, the largest source of measurement error is likely to be that managers' IAT scores are not a perfect measure of bias. Nosek et al. (2007) summarizes studies measuring the IAT's reliability over time and finds that individuals' scores on different IAT administrations have a correlation of approximately 0.56 , an effect that doesn't change with the length of time between testing. If the IAT is a combination of managers' true implicit bias and noise that is uncorrelated across test administrations, the coefficients of interest will be attenuated by a factor of approximately 1.8 due to the measurement error in the IAT score.

\subsection{Time Spent at Work}

CPs are absent less than $2 \%$ of days. Absence rates increase throughout the week, starting at a low of $0.7 \%$ on Monday and reaching $2.3 \%$ on Saturday; absence rates are even higher $(2.8 \%)$ on the rare occasion that workers work on Sunday. However, absences are not significantly different on days with morning or evening shifts.

Panel A of Table 4 shows the effect of manager bias on absence rates. The first column adds no controls, $X_{i s t}$. It shows that working with a manager with an IAT score one standard deviation higher leads minorities to have an absence rate one percentage point higher. The effect is large in magnitude (70\% of the mean) even before corrections for measurement error. The subsequent two columns add (1) day of the week fixed effects and controls for the shift starting in the early morning and ending in the late evening and (2) date fixed effects, respectively. Adding these controls does not change the coefficient of interest.

The final column includes as controls a dummy for the manager being a minority and an indicator for the worker and the manager both being minorities. Because there are so few minority managers, we do not estimate these terms precisely. However, including these terms does not change the coefficient of interest (nor does simply eliminating days with minority managers). Thus, the effect of working with a biased manager appears to result from the manager's bias, not the manager's group affiliation. 
Throughout the panel, the measured effect of working with a biased manager for majority workers is negative, suggesting that non-minorities are less likely to be absent when scheduled to work with biased managers. However, this effect is always insignificant and smaller than the effect for minority workers.

We next investigate the effect of working with biased managers on the amount of time spent at work. Panel B of Table 4 replicates Panel A where the dependent variable, $y_{i s t}$, is the actual number of minutes the $\mathrm{CP}$ worked in excess of the number of minutes she was scheduled to work. These regressions are limited to days workers show up to work..$^{20}$

The panel shows that even on days that minorities are not absent, they work less when paired with a biased manager. When working with a manager one standard deviation more biased, they work about 3.3 fewer minutes. This is about one twelfth of a standard deviation before correcting for measurement error. As in the prior panel, the result is robust to the addition of controls and is not driven by the manager's minority status. However, unlike in the previous panel, the point estimates do not suggest that majority workers spend more time at work when scheduled to work with biased managers.

Aside from being absent, there are three main ways that a worker could spend less time at work: she could arrive later, leave earlier, or take longer breaks. We find that working with a biased manager primarily leads minorities to leave work earlier. Table 5 presents regressions similar to those in Table 4B, where the dependent variables are different aspects of time spent at work. There is no significant effect of manager bias on arrival time: in fact, the far-from-significant point estimate suggests that minority workers arrived earlier when working with biased managers. Similarly, there is no significant effect of manager bias on break time. However, a minority worker paired with a manager one standard deviation more biased left the store 3.7 minutes earlier on average. This is not driven by minorities leaving before the end of their shift: if anything, minorities were more likely to stay until shift end when working with biased managers. But, they were substantially less likely to stay after. ${ }^{21}$ This could be because biased managers biased managers were less likely to ask

\footnotetext{
${ }^{20}$ Note that because we eliminate days workers were absent, these regressions could be biased. Because we include worker fixed effects, for this bias to be driving our results it would have to be the case that minority workers would have chosen to work more than average (relative to their schedules) on the days that being scheduled to work with a biased manager led them to be absent. Instead, we believe that any bias likely attenuates our results. It seems reasonable that the days that minority workers did not show up as a result of being paired with biased managers are days that they would have worked relatively less had they arrived.

${ }^{21}$ Consistent with this, when we adjust our specification to include the bias of the manager on duty at the end of the shift, instead of the average manager bias throughout the day, the effect on minutes worked more than doubles to -6.71 (without controls) and -7.18 (with our full controls). However, neither of these estimates is significant at conventional levels, with p-values of 0.132 and 0.114 , respectively. Appendix Figure 1 shows the measured effect of manager bias on minorities staying different lengths of time after the shift ends: from staying any time after the end of the shift to staying up to five hours after the shift ends. Manager bias appears to decrease the number of minutes minorities stay after their shifts throughout the distribution.
} 
minority workers to stay late or because minorities were less likely to agree when working with biased managers.

While we do not have information on workers' pay, we can use estimates of time spent at work to estimate how much more minorities would earn (relative to majorities) if they worked only with unbiased managers. Re-estimating the minutes worked regression including days that workers were absent suggests that, for each standard deviation increase in manager bias minorities spend 8 fewer minutes per day at work. Eliminating manager bias would increase the time minorities spent at work and their pay by $2.5 \%$ (before correcting for measurement error).

\subsection{Performance while at Work}

We now examine the effect of manager bias on minority performance while at work, first considering the number of articles per minute scanned. This is one of the performance metrics over which workers have the most control and one of the metrics the firm cares most about. In each store, a list of workers' average articles per minute scanned is posted in the break room each week.

On average, CPs scanned 18.5 articles per minute. There are not large day-of-the-week effects in scanning speed, except that workers are exceptionally slow (1.2 articles per minute slower on average) on the few occasions when they have to work Sundays. Workers also scan articles more slowly on shifts that begin in the early morning.

Before we show our causal estimates, Figures 1A and B plot the relationship between manager bias and articles per minute scanned for minorities (Panel A) and majorities (Panel B). Each point plots the average articles per minute scanned by either minority or majority workers on days that they faced the indicated level of bias. Manager IAT scores are aggregated into bins of 0.2 and the size of the point indicates the number of observations in each bin. These graphs do not remove any individual or store fixed effects, so differences in scanning speed may result from cross-store differences in the types of workers hired or items purchased, instead of the bias workers are exposed to. Nonetheless, these graphs tell the same story as the regressions: minorities tend to scan slower when working with more-biased managers. Majority workers appear to scan more quickly when working with more-biased managers, but the effect for majorities is smaller than the effect for minorities.

Table $6 \mathrm{~A}$ replicates the format of Table $4 \mathrm{~A}$, showing the effect of manager bias on scanning

For example, it decreases the probability that a minority will stay at least an hour and a half after her shift ends by 1.5 percentage points. If these minorities who would have stayed at least 90 minutes instead leave at the end of their shifts, a decrease in these longer shifts would account for approximately half of the overtime effect. 
speed. To the extent that cashiers' performance at work is affected by the bias of managers they actually work with (as opposed to the bias of the managers they are scheduled to work with), the coefficients in this table can be thought of as the reduced form for an instrumental variables regression in which the bias of the scheduled manager instruments for the bias of the manager on duty. These two bias measures have a high correlation (0.93).

Table $6 \mathrm{~A}$ shows that working with biased managers leads minority workers to scan items more slowly. Being scheduled to work with a manager who scored one standard deviation higher on the IAT leads the average minority worker to scan 0.28 fewer items per minute. (The standard deviation of articles per minute is 2.9.) Unreported regressions show that manager bias does not appear to induce minorities to perform extremely poorly (in the bottom 15\%), but otherwise it affects the entire distribution of performance: from making minorities more likely to perform poorly (in the bottom 25\%) to making them less likely to perform extremely well. The coefficients indicate that biased managers may cause majority workers to scan articles more quickly, though this effect is only significant at the $10 \%$ level and in only one of the specifications.

Panel B of Table 6 investigates the effect of manager bias on inter-customer time, the amount of time that a cashier spends between finishing one customer's transaction and starting to scan the next customer's items. While this is not an oft-discussed performance metric in the store, it directly affects the speed at which the lines move. On average, workers spend just under thirty seconds between customers. Working with a manager who is one standard deviation more biased leads minority workers to spend about 1.2 more seconds between customers. This is approximately one tenth of a standard deviation or $4 \%$ longer.

In contrast, there is no effect of manager bias on payment time: the time between the scanning of a customer's final item and the end of the transaction, during which time the customer is paying. See Appendix Table 5 for estimates. This may be because payment time largely depends on the customer.

Appendix Table 6 shows that our results on the effect of manager bias are not driven by the other manager characteristics in our data: manager position in the firm, age, or gender. Appendix Table 7 shows the results are robust to using different definitions of minority status. Panel A considers as minorities only workers with either a first or last name of North African origin (and eliminates remaining workers with names of Sub-Saharan African origin), while Panel B does the reverse. The effects of manager bias on workers of North and Sub-Saharan African origin are similar. Panel C utilizes the original definition of minority workers, but considers as majority workers only workers who have both a first and last name of European origin (eliminating workers of indeterminate, mixed, or other origins). The results are virtually unchanged. The results are also robust to using a wild 
cluster bootstrap, a method suggested for small numbers of clusters (Cameron et al., 2008). ${ }^{22}$

An alternative explanation for our results is that CPs' performance does not respond to managers, but instead responds to senior cashiers who tend to work disproportionately with certain managers. More-biased workers may sort towards more-biased managers or senior minority workers may sort away from more-biased managers. ${ }^{23}$ It is difficult to test this theory directly since we do not have data on senior cashiers (just managers and CPs). However, we think this explanation is unlikely. While senior cashiers have some control over their schedules, they can only submit preferences over the times they work, not the people they work with. The way that a worker could attempt to work with a particular manager is by requesting certain shifts that the manager prefers. For example, if a biased manager tended to work Monday mornings, but not Tuesday afternoons, biased senior cashiers who wanted to work with this manager could request these times. There is a limit to how much workers can control their schedules: because the firm values everyone doing their "fair share" of different kinds of shifts, it has included this as a constraint in the assignment algorithm.

Appendix Table 8 shows that the measured effects of manager bias on minority performance are virtually identical if we control for shift (day of the week $\times$ morning or evening) within store and thus the likely sorting of senior cashiers. While senior workers could sort towards managers in a more sophisticated way, the fact that this most likely method explains none of the effect of manager bias suggests that senior cashier sorting is not driving our results.

Why do firms employ biased managers given that biased managers negatively impact minority performance? One explanation is that biased managers do not decrease average performance. Regressing worker performance on manager IAT scores indicates that biased managers don't generate worse average worker performance. While biased managers depress the performance of minority workers, minorities are a small share (28\%) of the entire workforce. For three out of the four main outcomes, point estimates suggest that biased managers (insignificantly) improve majority worker performance. Because managers can choose when they work, the estimates of manager bias on overall worker performance may include the effects of different store conditions and do not necessarily isolate managers' effect on worker performance. Nevertheless, adding controls for shift characteristics does not change the

\footnotetext{
${ }^{22}$ Using a wild cluster bootstrap, the p-values for the coefficients on the minority worker $\times$ manager bias term in the first columns of Tables 4 and 6 are 0.016 (absences), 0.009 (minutes worked), 0.049 (articles scanned per minute), and 0.093 (inter-customer time).

${ }^{23}$ Even though we do not think this describes what is happening in the stores, this alternative explanation might have similar implications. If minority performance is negatively affected by more-biased senior workers, then the bias of more senior store personnel would still be harming minority workers. If senior minority workers prefer not to work with biased managers, then this explanation would still include manager bias affecting minorities' work patterns.
} 
estimates.

\subsection{Heterogeneity in Effects}

Table 7 examines how the impact of bias evolves over the contract (Panel A) and how it differs in more- and less-diverse stores (Panel B). We focus on articles per minute scanned because it is important to the store and has continuous variation.

The two columns in Panel A show the results of estimating Equation (2), where observations are limited to promotions for which we have early- and late-week data, respectively. Appendix Table 9 shows that promotions for which we have early- and late-week data have similar worker and manager characteristics. In fact, many stores are included in both regressions because they have one promotion with early-week data and one promotion with late-week data.

CPs become more productive over time. In the latter part of the contract, workers scan two more articles per minute than they do in the early part. The negative effect of manager bias on minority performance also appears to increase over time. The effect of the bias is estimated to be twice as large in the latter weeks of the contract as it is in the early weeks, though the coefficients are not significantly different.

Panel B shows the effect of manager bias by workforce diversity. While we do not have data on any non-CP workers, we ask managers about the diversity of their stores in the manager survey. Since it is illegal to directly solicit data on ethnicity, we ask managers the fraction of workers that they have managed that come from "sensitive urban zones" (ZUS). ZUS have high concentrations of immigrants and first generation citizens (ONZUS, 2011) and ZUS residence has been used as a signal of minority status in a study of anonymous resumes (Behaghel et al., 2015). We average manager responses within a store to create a proxy for store diversity. The reported fraction of workers who come from ZUS is positively correlated with the fraction of minority CPs in our data. Panel B shows that the negative effect of manager bias is driven by stores with relatively little diversity. In less-diverse stores, minority workers scan 0.48 fewer articles per minute for each standard deviation increase in manager bias. Appendix Table 9 shows that there are other differences between more- and less-diverse stores, though none of these differences seem to drive the effect of manager bias. ${ }^{24}$

\footnotetext{
${ }^{24}$ More-diverse stores have more male workers and male managers (both significant at the $10 \%$ level) and younger managers (significant at the 1\% level) than do less-diverse stores.
} 


\section{Evidence on Mechanisms}

In this section, we use administrative data and data from the worker survey to test the predictions of the discrimination theories presented in Section 3. The last column of Table 1 shows the results of these tests.

The data seem inconsistent with managers having animus towards minorities. Minorities do not perceive biased managers as disliking them. In the worker survey, we asked workers to rank their managers on the extent to which the manager liked the worker and the manager was likely to recommend the worker for promotion. We use workers' answers to order managers from the 1 (the lowest ranked) to $\mathrm{N}$ (the highest ranked). ${ }^{25}$ The first two columns of Table 8A show the results of estimating Equation (2) with workers' rankings of their managers on these two dimensions as the dependent variables. While neither coefficient is significant, both are positive, suggesting that, if anything, minorities perceived biased managers as liking them more than other managers. We also asked workers to rate how much they enjoyed working with each manager. Minorities again rated biased managers insignificantly more positively.

To assess whether biased managers activated minorities' negative stereotypes, we asked workers which managers initially made the worker feel most confident in their abilities. There is no evidence that biased managers made minorities anxious about confirming stereotypes or activated self-stereotypes of poor performance - minorities rate biased managers as making them feel insignificantly more confident about their abilities (Table 8A). Though, as discussed in Section 3, this does not rule out an explanation whereby stereotypes are activated subconsciously.

Panel B analyzes whether biased managers are differentially likely to assign minorities to unpleasant tasks. Animus would lead them to do so, while avoiding interacting with minorities would lead them to be less likely to assign minorities to additional tasks, regardless of whether the tasks are pleasant or unpleasant. The first two columns of Table $8 \mathrm{~B}$ examine workers' register assignment and the desirability of their break times. ${ }^{26}$ Since all cashiers need to be assigned to a register and given breaks, these two task assignments test for animus, but not whether biased managers avoid interacting with minorities. Biased managers do not assign minorities to unpleasant registers or break times.

The final column considers assignment to cleaning duties. Telling a worker to shut down her register and start cleaning requires interaction. Cleaning is typically considered to be

\footnotetext{
${ }^{25}$ We eliminate managers workers indicated not remembering from this ranking since workers almost never ranked these managers. We analyze whether workers remembered their managers separately.

${ }^{26}$ Managers choose when workers can take their breaks, but not how much break time workers receive, which is stipulated in workers' contracts.
} 
cashiers' least pleasant task. Consistent with biased managers avoiding minorities, but inconsistent with animus, biased managers are significantly less likely to assign minorities to cleaning duties. ${ }^{27}$ This is also consistent with the idea that biased managers may be less likely to ask minorities to stay late. The interaction theory may also explain why the effect of manager bias is larger in stores with less diversity: it may be more difficult for managers to avoid minority workers when a larger share of the workforce is minority.

To further test the interaction theory, we asked CPs to rate the extent to which they remembered each manager. We utilize remembering a manager (ranking the manager at least two out of 10) as an indicator of the amount of interaction the worker and manager had. Workers performed much better when working with managers with whom they interacted more. The first column of Table 9A shows that workers scanned 1.5 more articles per minute when working with a manager they later remembered. However, workers did not perform better when working with managers they had been scheduled to work with more often (Column 2), nor does the effect on worker performance of remembering the manager change when we control for the amount of time spent working together (Column 3). The impact of worker-manager interaction on scanning speed also does not decrease when we add manager fixed effects (Column 4). Taken together, this suggests that worker-manager interaction within a shift leads workers to perform substantially better. This is akin to Mas and Moretti (2009), which finds that cashiers exert more effort when their performance is being noticed by coworkers they value.

Minorities report interacting less with biased managers: they were about 1.5 percentage points less likely to remember managers one standard deviation more biased (Table 9B, Column 1). ${ }^{28}$ The final columns in Table $9 \mathrm{~B}$ suggest how worker-manager interaction affects the measured impact of manager bias on minority performance. While the results are imprecise, when we limit the sample to days when the worker remembered the manager, the effect of manager bias on minority performance falls by $25 \%$.

Summarizing our results, we find the strongest evidence for the theory in which biased managers feel less comfortable with minority workers, so they interact less with them and are less likely to assign them to new tasks, even unpleasant ones. We find no evidence of animus: minorities do not report that biased managers disliked them or assigned them to unpleasant tasks. We have less clear evidence on whether stereotypes play a role: we do not find that biased managers made minorities consciously anxious about their abilities, but this does not rule out that they activated stereotypes on a subconscious level.

\footnotetext{
${ }^{27}$ Managers concerned with appearing biased might be particularly concerned with the optics of assigning minorities to clean.

${ }^{28}$ Unsurprisingly, workers were more likely to remember managers they were scheduled to work with more.
} 
Next, we assess whether manager bias feeds back into statistical discrimination in hiring. If it does, minorities should perform better than majorities when they do not face manager bias, but as a result of manager bias, minorities may not perform better on average. This is consistent with what we find. Table 10 presents estimates from the regression

$$
y_{i s t}=\alpha+\beta \text { minority }_{i}+\delta_{s}+\varepsilon_{i s t}
$$

where $y_{i s t}$ is a metric of performance of worker $i$ in store $s$ on date $t$ and $\delta_{s}$ are store fixed effects. The coefficient of interest, $\beta$, shows how minority workers' performance compares to the performance of majority workers in the same store. Panel A includes all days. It shows that minority workers' average performance is statistically indistinguishable from that of majority workers. However, Panel B compares minority and majority workers' performance on days when they work with unbiased managers. (Because most managers are biased, this is only a small fraction of days.) On days when workers spend at least half their time with unbiased managers, minority workers perform substantially better than do non-minority workers. They are approximately half as likely to be absent, they scan 0.75 more articles per minute, and they take two fewer seconds between customers. Thus, while overall minority and majority workers perform similarly, this analysis suggests that if minority and majority workers both worked in a workplace without manager bias, minority workers would perform better. $^{29}$

We can also use this design to evaluate the magnitude of the impact of manager bias on minority performance. We first estimate the number of customers served by each worker on each day by combining the time she spent at work with her average articles per minute scanned, inter-customer time, and payment time. We assume that the average customer has 25 items, though our results are not very sensitive to this assumption. We also assume that cashiers spend all day at their registers receiving customers. To the extent that this is not true, but manager bias has similar impacts on minority productivity on other tasks, this can still be thought of as a summary measure of performance. Under these assumptions, the average majority worker serves 162 customers per day. The average minority serves an additional 2.8 customers, controlling for store fixed effects, a difference which is far from significant (Table 10A). However, on days with unbiased managers, the average minority cashier serves 14 customers more per day than does the average majority (Table 10B). This

\footnotetext{
${ }^{29}$ Another test for statistical discrimination would be to assess whether hired minorities have better observable characteristics than hired majorities. We have only one pre-employment characteristic that should have a clear relationship with productivity: educational attainment. Consistent with statistical discrimination, minorities are more than three times as likely to have education above high school as are majority workers (16\% vs. $5 \%)$ and that this difference remains nearly as large (9.1 percentage points) when store fixed effects are added.
} 
is a $9 \%$ increase in average performance. These results imply that the average minority worker is at the 53rd percentile of average cashier performance, while the average minority working with unbiased managers would be at the 79th percentile.

These conclusions would be erroneous if minority workers were simply intertemporally substituting effort towards days with unbiased managers. If they were fully intertemporally substituting, manager bias would not affect average minority performance, it would just lead minorities to perform worse on some days and better on others. The fact that minorities performed better on days without bias would not indicate their higher general productivity or be evidence of statistical discrimination. However, we provide two tests that suggest that minorities are not simply intertemporally substituting effort towards days with unbiased managers. Table 11 shows the effect of working with a more-biased manager on one day on the worker's performance in the rest of the week. ${ }^{30}$ Under intertemporal substitution, working with a more-biased manager on one day should lead minorities to perform better in the rest of the week. We find no evidence that this is the case. In fact, minorities scan items significantly slower in the rest of the week when they spend one more day with a more-biased manager.

We can also look at workers' response to manager bias aggregated over longer periods (Appendix Table 10). If a worker is intertemporally substituting her effort within a given period (e.g., at the week or two-week level), performance should be uncorrelated with manager bias at that level of aggregation. However, we find no evidence that the impact of manager bias is attenuated when performance is aggregated over longer periods. For absences, the measured effect of manager bias is relatively constant with the level of aggregation, though it is no longer statistically significant once the data is aggregated. For articles per minute, the measured effect increases as the level of aggregation increases. Consistent with the results in Table 11, this may indicate that there are some cumulative effects of manager bias on scanning speed.

\section{Conclusion}

The paper has shown that working with biased managers leads minority workers to perform more poorly. When scheduled to work with more-biased managers, minority cashiers are more likely to be absent and they leave work earlier. Because these workers are paid based on time worked, this leads to a loss in wages for minority workers. Minorities also scan items more slowly and take more time between customers when working with biased managers.

\footnotetext{
${ }^{30}$ We control for manager bias in the rest of the week and its interaction with the worker's minority status to eliminate the effects of intra-week correlation in manager bias.
} 
It does not appear that this results from manager animus. Instead, it appears that biased managers feel uncomfortable with minority workers and interact less with them, leading minority cashiers to exert less effort.

These results come from one setting: entry-level cashiers in a large French grocery store chain. However, they may be applicable to many other workplace settings. In our setting, biased managers' discomfort with minorities can lead them to monitor minorities less, assign minorities to new tasks less frequently, and not ask minorities to stay late. In other settings, interacting less with minority employees may have larger consequences if it also leads biased managers to train, mentor, advise, or challenge minorities less.

Our results raise the question of the type of policy responses that could be used to ameliorate the impact of manager bias on minority workers. One set of potential policies would aim to directly reduce implicit bias. Beaman et al. (2009) finds that having female leaders reduces implicit bias against women. Outside of the workplace, Rao (2014) and Boisjoly et al. (2006) find that exposure to a group can reduce bias against it. Another set of potential policies would attempt to mitigate the effect of manager bias by directly targeting manager actions. For example, these interventions could encourage managers to interact with all workers equally or provide more specific guidelines about how to manage workers. Investigating the effects of such policies is an interesting question for future research.

\section{References}

Agerström, J., R. Carlsson, and D.-O. Rooth (2007): "Ethnicity and obesity: Evidence of implicit work performance stereotypes in Sweden," Working Paper, IFAUInstitute for Labour Market Policy Evaluation.

Amodio, D. M., And P. G. Devine (2006): "Stereotyping and evaluation in implicit race bias: Evidence for independent constructs and unique effects on behavior," Journal of Personality and Social Psychology, 91(4), 652.

Arrow, K. (1973): "The theory of discrimination," Discrimination in Labor Markets, 3(10), $3-33$.

Banse, R., J. Seise, and N. Zerbes (2001): "Implicit attitudes towards homosexuality: Reliability, validity, and controllability of the IAT," Zeitschrift für Experimentelle Psychologie, 48(2), 145-160.

Beaman, L., R. Chattopadhyay, E. Duflo, R. Pande, and P. Topalova (2009): 
"Powerful women: Does exposure reduce prejudice?," Quarterly Journal of Economics, 124(4), 1497-1540.

Becker, G. S. (1957): The Economics of Discrimination. University of Chicago Press, Chicago.

Behaghel, L., B. Crépon, and T. Le Barbanchon (2015): "Unintended effects of anonymous résumés," American Economic Journal: Applied Economics, 7(3), 1-27.

Bertrand, M., D. Chugh, and S. Mullainathan (2005): "Implicit discrimination," American Economic Review: Papers and Proceedings, 95(2), 94-98.

Boisjoly, J., G. J. Duncan, M. Kremer, D. M. Levy, and J. Eccles (2006): "Empathy or antipathy? The impact of diversity," American Economic Review, 96(5), 1890-1905.

Bordalo, P., K. Coffman, N. Gennaioli, and A. Shleifer (forthcoming): "Stereotypes," Quarterly Journal of Economics.

Cameron, A. C., J. B. Gelbach, and D. L. Miller (2008): "Bootstrap-based improvements for inference with clustered errors," Review of Economics and Statistics, 90(3), $414-427$.

Conte, S., And G. C. Loury (1993): "Will affirmative-action policies eliminate negative stereotypes?," American Economic Review, 83(5), 1220-1240.

Coffman, K. B. (2014): "Evidence on self-stereotyping and the contribution of ideas," Quarterly Journal of Economics, 129(4), 1625-1660.

DEE, T. S. (2004): "Teachers, race, and student achievement in a randomized experiment," Review of Economics and Statistics, 86(1), 195-210.

- (2005): "A teacher like me: Does race, ethnicity, or gender matter?," American Economic Review, 95(2), 158-165.

Dovidio, J. F., And S. L. GaertneR (2008): "New directions in aversive racism research: Persistence and pervasiveness," in Motivational Aspects of Prejudice and Racism, pp. 4367. Springer.

Dovidio, J. F., K. Kawakami, and S. L. Gaertner (2002): "Implicit and explicit prejudice and interracial interaction," Journal of Personality and Social Psychology, 82(1), 62. 
Egloff, B., And S. C. Schmukle (2002): "Predictive validity of an Implicit Association Test for assessing anxiety," Journal of Personality and Social Psychology, 83(6), 1441.

Friese, M., M. Bluemke, and M. Wänke (2007): "Predicting voting behavior with implicit attitude measures: The 2002 German parliamentary election," Experimental Psychology, 54(4), 247.

Garthwaite, C., T. Gross, and M. J. Notowidigdo (2014): "Public health insurance, labor supply, and employment lock," Quarterly Journal of Economics, 129(2), 653-696.

Giuliano, L., D. I. Levine, and J. Leonard (2009): "Manager race and the race of new hires," Journal of Labor Economics, 27(4), 589-631.

Green, A. R., D. R. Carney, D. J. Pallin, L. H. Ngo, K. L. Raymond, L. I. IEZzONI, AND M. R. BANAJI (2007): "Implicit bias among physicians and its prediction of thrombolysis decisions for black and white patients," Journal of General Internal Medicine, 22(9), 1231-1238.

Greenwald, A. G., D. E. McGhee, and J. L. Schwartz (1998): "Measuring individual differences in implicit cognition: The Implicit Association Test," Journal of Personality and Social Psychology, 74(6), 1464.

Greenwald, A. G., B. A. Nosek, and M. R. Banaji (2003): "Understanding and using the Implicit Association Test: I. An improved scoring algorithm," Journal of Personality and Social Psychology, 85(2), 197-216.

Greenwald, A. G., T. A. Poehlman, E. L. Uhlmann, and M. R. Banaji (2009): "Understanding and using the Implicit Association Test: III. Meta-analysis of predictive validity," Journal of Personality and Social Psychology, 97(1), 17.

Hahn, A., C. M. Judd, H. K. Hirsh, and I. V. Blair (2014): "Awareness of implicit attitudes," Journal of Experimental Psychology: General, 143(3), 1369-1392.

Haider, A. H., J. Sexton, N. Sriram, L. A. Cooper, D. T. Efron, S. Swoboda, C. V. Villegas, E. R. Haut, M. Bonds, P. J. Pronovost, et al. (2011): "Association of unconscious race and social class bias with vignette-based clinical assessments by medical students," Journal of the American Medical Association, 306(9), 942-951.

Hebl, M. R., J. B. Foster, L. M. Mannix, and J. F. Dovidio (2002): "Formal and interpersonal discrimination: A field study of bias toward homosexual applicants," Personality and Social Psychology Bulletin, 28(6), 815-825. 
HJort, J. (2014): "Ethnic divisions and production in firms," Quarterly Journal of Economics, 129(4), 1899-1946.

Hu, X., J. P. Rosenfeld, and G. V. Bodenhausen (2012): "Combating automatic autobiographical associations: The effect of instruction and training in strategically concealing information in the Autobiographical Implicit Association Test," Psychological Science, 23(10), 1079-1085.

KIM, D.-Y. (2003): "Voluntary controllability of the Implicit Association Test (IAT)," Social Psychology Quarterly, 66(1), 83-96.

Lane, K. A., M. R. Banaji, B. A. Nosek, and A. G. Greenwald (2007): "Understanding and using the Implicit Association Test: IV. What we know (so far) about the method," in Implicit Measures of Attitudes, ed. by B. Wittenbrink, and N. Schwarz, pp. 59-102. The Guilford Press.

Lundberg, S. J., and R. Startz (1983): "Private discrimination and social intervention in competitive labor market," American Economic Review, 73(3), 340-347.

Mas, A., and E. Moretti (2009): "Peers at work," American Economic Review, 99(1), $112-145$.

McConnell, A. R., and J. M. Leibold (2001): "Relations among the Implicit Association Test, discriminatory behavior, and explicit measures of racial attitudes," Journal of Experimental Social Psychology, 37(5), 435-442.

Mooney, C. (2014): "Across America, whites are biased and they don't even know it," The Washington Post: Wonkblog.

Nosek, B. A., A. G. Greenwald, and M. R. Banaji (2007): "The Implicit Association Test at age 7: A methodological and conceptual review," in Automatic Processes in Social Thinking and Behavior, ed. by J. Bargh, pp. 265-292. Psychology Press.

ONZUS (2011): "Observatoire National des Zones Urbaines Sensibles," Discussion paper, Secrétariat général du Comité interministériel des villes.

Phelps, E. S. (1972): "The statistical theory of racism and sexism," American Economic Review, 62(4), 659-661.

Price, J., And J. Wolfers (2010): "Racial discrimination among NBA referees," Quarterly Journal of Economics, 125(4), 1859-1887. 
RAO, G. (2014): "Familiarity does not breed contempt: Diversity, discrimination and generosity in Delhi schools," Working Paper.

Rooth, D.-O. (2010): "Automatic associations and discrimination in hiring: Real world evidence," Labour Economics, 17(3), 523-534.

Rosenthal, R., and L. Jacobson (1968): "Pygmalion in the classroom," Urban Review, $3(1), 16-20$.

Smith-Mclallen, A., B. T. Johnson, J. F. Dovidio, and A. R. Pearson (2006): "Black and white: The role of color bias in implicit race bias," Social Cognition, 24(1), $46-73$.

Stauffer, J. M., and M. R. Buckley (2005): "The existence and nature of racial bias in supervisory ratings," Journal of Applied Psychology, 90(3), 586-591.

Stoll, M. A., S. Raphael, and H. J. Holzer (2004): "Black job applicants and the hiring officer's race," Industrial \& Labor Relations Review, 57(2), 267-287. 


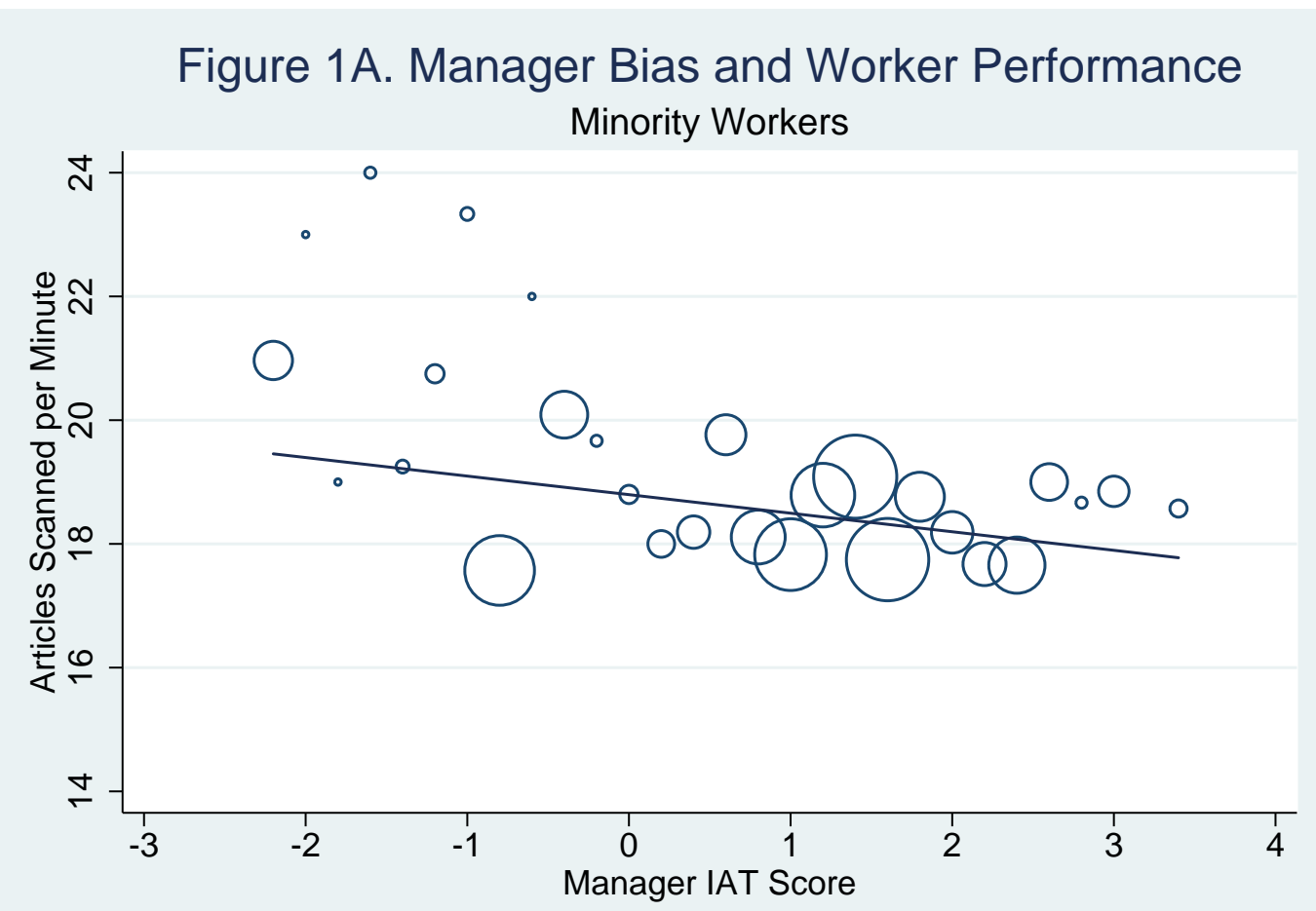

Note: The size of each marker indicates the number of observations in the bin.

Figure 1B. Manager Bias and Worker Performance Majority Workers

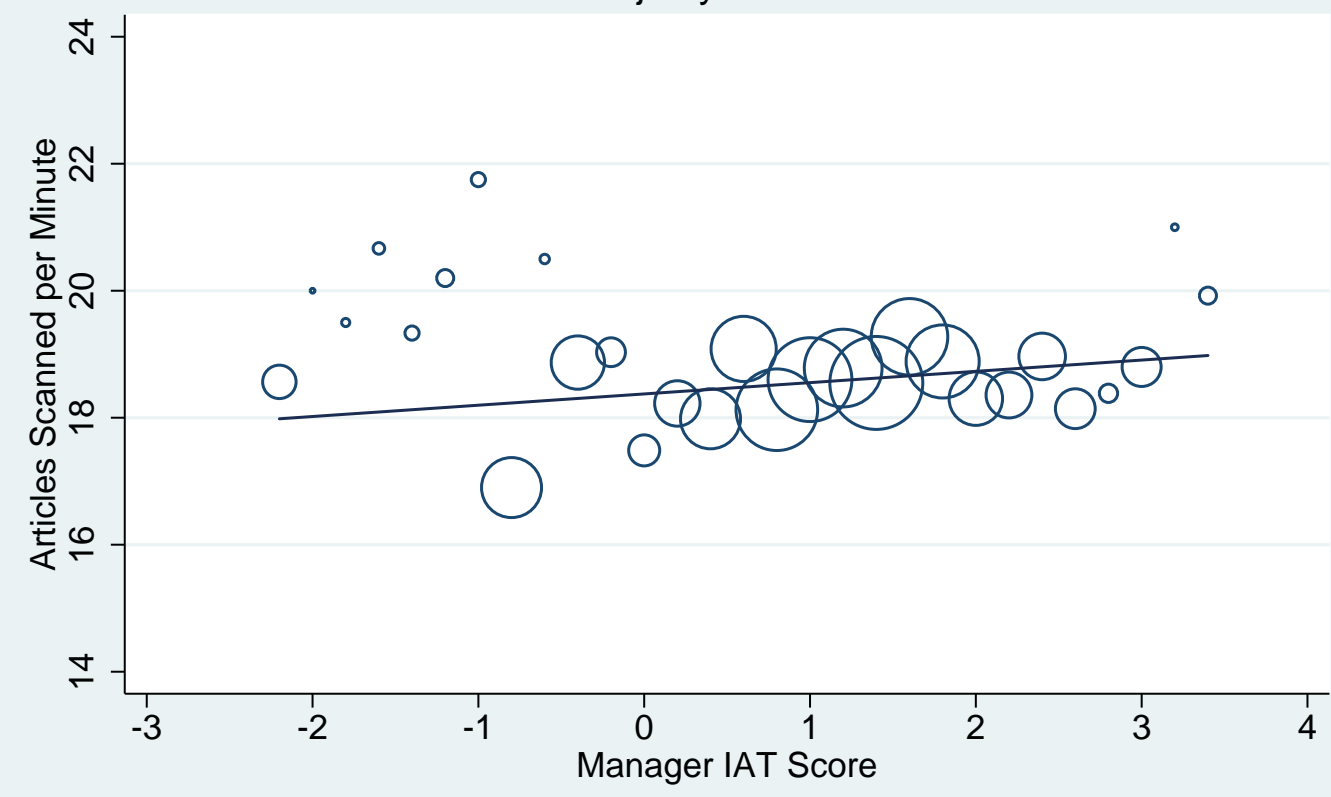

Note: The size of each marker indicates the number of observations in the bin. 
Table 1. Theories of Discrimination and Their Predictions

\begin{tabular}{|c|c|c|c|c|}
\hline & $\begin{array}{l}\text { Beckerian Taste for } \\
\text { Discrimination }\end{array}$ & $\begin{array}{c}\text { Less Interaction and } \\
\text { Statistical Discrimination }\end{array}$ & $\begin{array}{c}\text { Stereotypes and Statistical } \\
\text { Discrimination }\end{array}$ & Empirical Findings \\
\hline $\begin{array}{l}\text { Biased managers are [more/less] likely } \\
\text { to give minorities unpleasant tasks }\end{array}$ & More & Less & -- & Less \\
\hline $\begin{array}{l}\text { Minorities report that biased managers } \\
\text { dislike them }\end{array}$ & Yes & -- & -- & No \\
\hline $\begin{array}{l}\text { Biased managers spend less time with } \\
\text { minorities }\end{array}$ & -- & Yes & -- & Yes \\
\hline $\begin{array}{l}\text { Biased managers make minorities less } \\
\text { confident in their abilities }\end{array}$ & -- & -- & Yes & No (not consciously) \\
\hline $\begin{array}{l}\text { Minorities are more productive than } \\
\text { majority workers when they do not face } \\
\text { bias }\end{array}$ & -- & Yes & Yes & Yes \\
\hline
\end{tabular}

Note: "--" indicates that a particular model does not make a clear prediction. 


\begin{tabular}{|c|c|c|c|c|}
\hline \multirow[b]{3}{*}{ A. Worker Characteristics } & \multicolumn{2}{|c|}{ Administrative Data Sample } & \multicolumn{2}{|c|}{ Worker Survey Sample } \\
\hline & $\begin{array}{l}\text { All Observations from } \\
\text { Included Stores }\end{array}$ & $\begin{array}{l}\text { Regression Sample } \\
\text { (Observations with } \\
\text { Manager IAT Scores) }\end{array}$ & $\begin{array}{c}\text { All Survey } \\
\text { Respondents }\end{array}$ & $\begin{array}{l}\text { Survey Respondent } \\
\text { Regression Sample }\end{array}$ \\
\hline & & & & \\
\hline Minority & $28 \%$ & $28 \%$ & $29 \%$ & $25 \%$ \\
\hline Male & $6.9 \%$ & $7.4 \%$ & $7.7 \%$ & $7.3 \%$ \\
\hline Age & & & 29.9 & 30.1 \\
\hline Number of Previous Jobs & & & 3.9 & 4.0 \\
\hline Less than High School Education & & & $58 \%$ & $61 \%$ \\
\hline High School Degree & & & $35 \%$ & $32 \%$ \\
\hline More than High School Education & & & $7 \%$ & $7 \%$ \\
\hline Number of Workers & 218 & 204 & 310 & 178 \\
\hline \multicolumn{5}{|l|}{ B. Manager Characteristics } \\
\hline Minority & $6 \%$ & $8 \%$ & & \\
\hline Male & $10 \%$ & $7 \%$ & & \\
\hline Level 4 (High Position) & $18 \%$ & $18 \%$ & & \\
\hline Age & 41.1 & 41.1 & & \\
\hline Average IAT Score (in Standard Devs) & & 1.35 & & \\
\hline Moderate to Severe Bias & & $66 \%$ & & \\
\hline Slight Bias & & $20 \%$ & & \\
\hline Little to No Bias & & $9 \%$ & & \\
\hline Preference for Minorities & & $4 \%$ & & \\
\hline Number of Managers & 154 & 119 & & \\
\hline \multicolumn{5}{|l|}{ C. Shift Characteristics } \\
\hline Scheduled Days per Week & 4.2 & 4.2 & & \\
\hline Scheduled Hours per Day & 7.2 & 7.2 & & \\
\hline Absent & $1.8 \%$ & $1.6 \%$ & & \\
\hline Minutes Worked in Excess of Schedule & -0.31 & -0.06 & & \\
\hline Articles Scanned per Minute & 18.5 & 18.5 & & \\
\hline Inter-Customer Time (Seconds) & 29.2 & 28.7 & & \\
\hline Payment Time (Seconds) & 50.7 & 50.8 & & \\
\hline Number of Shifts & 5,099 & 4,371 & & \\
\hline Number of Stores & 34 & 34 & 70 & 51 \\
\hline
\end{tabular}

Note: The first two columns of data provide descriptive statistics for the sample for whom we have administrative data. The first includes all observations from the 34 included stores, while the second includes only observations for which we have the manager's IAT score. The final two columns provide descriptive statistics for the worker survey sample. The first includes all survey respondents, while the second includes only those workers for whom we either have managers' IAT scores or performance data and are thus included in the analysis. Level 4 managers have a higher position in the store than the remaining managers. Manager age is reported as of January 1, 2012. Moderate to Severe Bias is defined as having a raw IAT score above 0.35, Slight Bias is defined as having a raw IAT score between 0.15 and 0.35, Little to No Bias is defined as having a raw IAT score between -0.15 and 0.15 , and Preference for Minorities is defined as having a raw IAT score below -0.15 . 


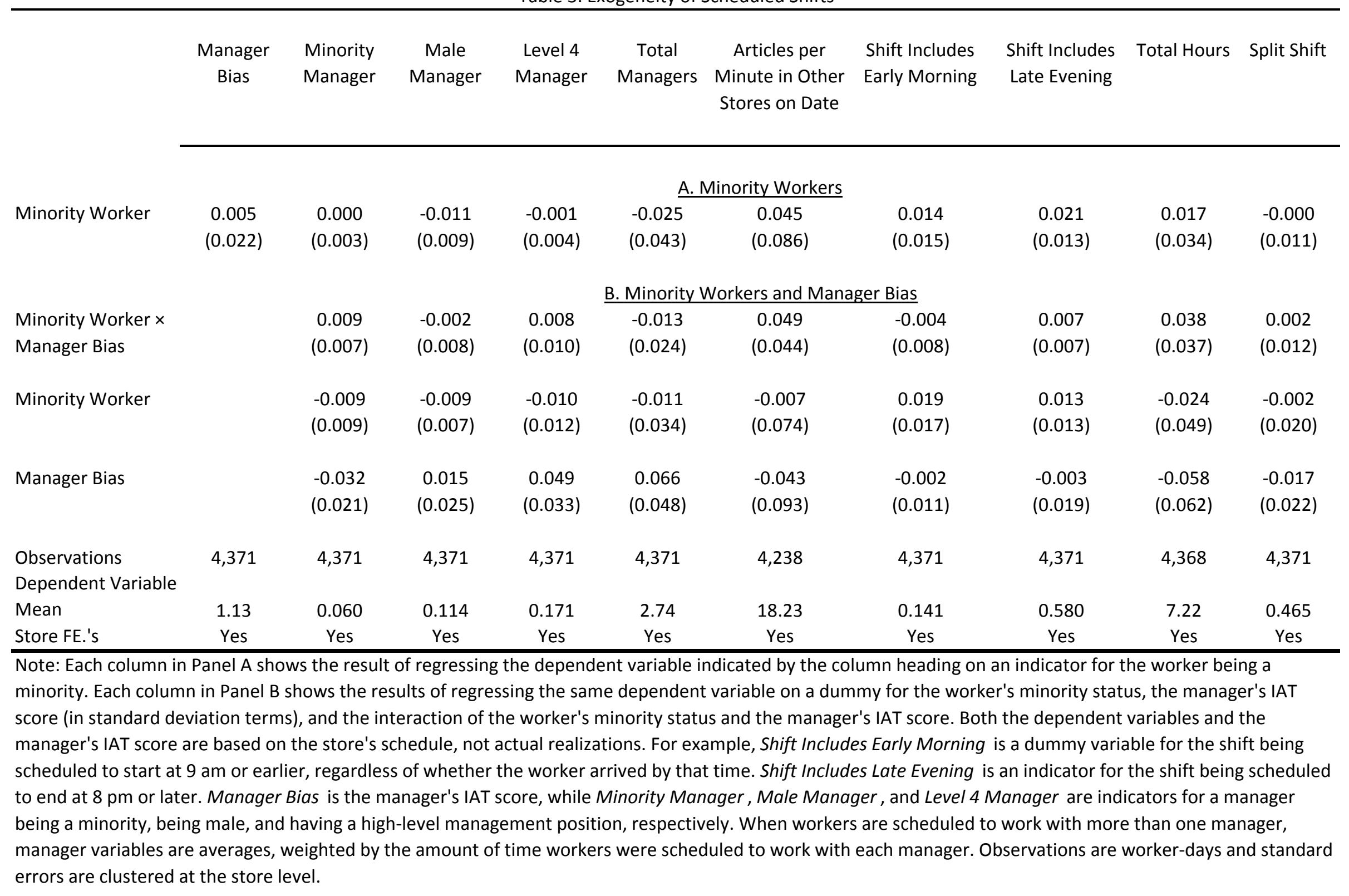




\begin{tabular}{|c|c|c|c|c|}
\hline \multirow[b]{2}{*}{ Minority Worker $x$} & \multicolumn{4}{|c|}{ A. Dependent Variable: Absence Indicator } \\
\hline & $0.0098 * *$ & $0.0095 * *$ & $0.0117 * * *$ & $0.0118 * * *$ \\
\hline Manager Bias & $(0.0039)$ & $(0.0040)$ & $(0.0042)$ & $(0.0043)$ \\
\hline \multirow[t]{2}{*}{ Manager Bias } & -0.0021 & -0.0021 & -0.0050 & -0.0052 \\
\hline & $(0.0031)$ & $(0.0032)$ & $(0.0040)$ & $(0.0042)$ \\
\hline Minority Worker $x$ & & & & 0.0081 \\
\hline Minority Manager & & & & $(0.0972)$ \\
\hline \multirow[t]{2}{*}{ Minority Manager } & & & & -0.0057 \\
\hline & & & & $(0.0153)$ \\
\hline Observations & 4,371 & 4,371 & 4,371 & 4,371 \\
\hline Dependent Variable Mean & 0.0162 & 0.0162 & 0.0162 & 0.0162 \\
\hline \multirow[t]{2}{*}{ R-squared } & 0.0005 & 0.0031 & 0.0835 & 0.0835 \\
\hline & \multicolumn{4}{|c|}{ B. Dependent Variable: Minutes Worked in Excess of Schedule } \\
\hline Minority Worker $x$ & $-3.295^{* *}$ & $-3.279 * *$ & $-3.327^{*}$ & $-3.237 *$ \\
\hline Manager Bias & $(1.550)$ & $(1.588)$ & $(1.687)$ & $(1.678)$ \\
\hline \multirow[t]{2}{*}{ Manager Bias } & -0.002 & -0.002 & -0.005 & -0.005 \\
\hline & $(1.141)$ & $(1.167)$ & (0.969) & (1.009) \\
\hline Minority Worker $x$ & & & & 0.349 \\
\hline Minority Manager & & & & $(10.501)$ \\
\hline \multirow[t]{2}{*}{ Minority Manager } & & & & -3.712 \\
\hline & & & & $(4.592)$ \\
\hline Observations & 4,163 & 4,163 & 4,163 & 4,163 \\
\hline Dependent Variable Mean & -0.068 & -0.068 & -0.068 & -0.068 \\
\hline R-squared & 0.001 & 0.008 & 0.129 & 0.129 \\
\hline Individual F.E.'s & Yes & Yes & Yes & Yes \\
\hline Day of the Week F.E.'s & No & Yes & No & No \\
\hline Morning/Evening F.E.'s & No & Yes & Yes & Yes \\
\hline Date F.E.'s & No & No & Yes & Yes \\
\hline
\end{tabular}

Note: Each column in each panel shows the result of regressing the dependent variable on the interaction of the worker's minority status and the manager's IAT score (in standard deviation terms), controlling for the manager's IAT score and worker fixed effects. The dependent variable in Panel $A$ is an indicator for the worker being absent. The dependent variable in Panel $B$ is the number of minutes worked in excess of the number of minutes the worker was scheduled to work. The first column includes no additional controls. The second column adds day of the week fixed effects, an indicator for the shift starting at 9 am or earlier, and an indicator for the shift ending at $8 \mathrm{pm}$ or later. The third column includes date fixed effects and drops the day of the week fixed effects. The last column adds a dummy for the manager being a minority and the interaction of the worker's and the manager's minority status. Observations are worker-days and standard errors are clustered at the store level. 


\begin{tabular}{|c|c|c|c|c|c|}
\hline & $\begin{array}{c}\text { Minutes Arrived Before } \\
\text { Shift Start }\end{array}$ & $\begin{array}{c}\text { Break Time } \\
\text { (Minutes) }\end{array}$ & $\begin{array}{l}\text { Minutes Stayed } \\
\text { After Shift End }\end{array}$ & $\begin{array}{c}\text { Stayed Until Shift } \\
\text { End }\end{array}$ & $\begin{array}{c}\text { Stayed at Least } 10 \\
\text { Minutes After Shift } \\
\text { End }\end{array}$ \\
\hline Minority Worker $x$ & 1.617 & 1.081 & $-3.773 * *$ & 0.014 & $-0.041^{*}$ \\
\hline Manager Bias & (1.858) & (1.381) & $(1.674)$ & $(0.024)$ & $(0.023)$ \\
\hline Manager Bias & $\begin{array}{c}0.633 \\
(1.358)\end{array}$ & $\begin{array}{l}-0.698 \\
(0.616)\end{array}$ & $\begin{array}{l}-0.402 \\
(1.027)\end{array}$ & $\begin{array}{l}-0.005 \\
(0.017)\end{array}$ & $\begin{array}{l}0.003 \\
(0.017)\end{array}$ \\
\hline Observations & 4,163 & 4,163 & 4,163 & 4,163 & 4,163 \\
\hline Dependent Variable Mean & 4.63 & 15.55 & 10.84 & 0.844 & 0.437 \\
\hline R-squared & 0.121 & 0.136 & 0.101 & 0.129 & 0.133 \\
\hline
\end{tabular}

Note: Each regression shows the result of regressing the dependent variable indicated by the column on the interaction of the worker's minority status and the manager's IAT score (in standard deviation terms), controlling for the manager's IAT score and worker fixed effects. The regressions additionally control for the manager's minority status, the interaction of the worker's and the manager's minority status, date fixed effects, and dummies for the shift starting at 9 am or earlier and ending at 8 pm or later. Observations are worker-days and standard errors are clustered at the store level. * ${ }^{* *}$ denote significance at the $10 \%$ and $5 \%$ levels, respectively. 


\begin{tabular}{|c|c|c|c|c|}
\hline & \multicolumn{4}{|c|}{ A. Dependent Variable: Articles Scanned per Minute } \\
\hline Minority Worker $\times$ & $-0.276 * *$ & $-0.279 * *$ & $-0.233 * *$ & $-0.249 * *$ \\
\hline Manager Bias & $(0.109)$ & $(0.111)$ & $(0.108)$ & $(0.111)$ \\
\hline \multirow[t]{2}{*}{ Manager Bias } & $0.140 *$ & 0.140 & 0.080 & 0.102 \\
\hline & $(0.083)$ & $(0.083)$ & $(0.065)$ & $(0.073)$ \\
\hline Observations & 3,601 & 3,601 & 3,601 & 3,601 \\
\hline Dependent Variable Mean & 18.53 & 18.53 & 18.53 & 18.53 \\
\hline \multirow[t]{2}{*}{ R-squared } & 0.001 & 0.013 & 0.195 & 0.195 \\
\hline & \multicolumn{4}{|c|}{ B. Dependent Variable: Inter-Customer Time (Seconds) } \\
\hline Minority Worker $\times$ & $1.213^{* *}$ & $1.228 * *$ & $1.417^{* *}$ & $1.360 * *$ \\
\hline Manager Bias & $(0.590)$ & $(0.553)$ & $(0.649)$ & $(0.665)$ \\
\hline \multirow[t]{2}{*}{ Manager Bias } & -0.648 & -0.571 & -0.656 & -0.580 \\
\hline & $(0.386)$ & $(0.376)$ & $(0.521)$ & $(0.534)$ \\
\hline Observations & 3,287 & 3,287 & 3,287 & 3,287 \\
\hline Dependent Variable Mean & 28.70 & 28.70 & 28.70 & 28.70 \\
\hline R-squared & 0.001 & 0.013 & 0.195 & 0.195 \\
\hline Individual F.E.'s & Yes & Yes & Yes & Yes \\
\hline Day of the Week F.E.'s & No & Yes & No & No \\
\hline Morning/Evening F.E.'s & No & Yes & Yes & Yes \\
\hline Date F.E.'s & No & No & Yes & Yes \\
\hline Manager Minority Variables & No & No & No & Yes \\
\hline \multicolumn{5}{|c|}{$\begin{array}{l}\text { Note: Each regression shows the result of regressing the dependent variable on the interaction } \\
\text { of the worker's minority status and the manager's IAT score (in standard deviation terms), } \\
\text { controlling for the manager's IAT score and worker fixed effects. The dependent variables are } \\
\text { the number of articles per minute scanned (Panel A) and the average number of seconds } \\
\text { between finishing one customer's transaction and scanning the next customer's items (Panel } \\
\text { B). The first column includes no controls. The second column adds day of the week fixed } \\
\text { effects, an indicator for the shift starting at } 9 \text { am or earlier, and an indicator for the shift } \\
\text { ending at } 8 \text { pm or later. The third column includes date fixed effects and drops the day of the } \\
\text { week fixed effects. The last column adds a dummy for the manager being a minority and the } \\
\text { interaction of the worker's and the manager's minority status. Observations are worker-days } \\
\text { and standard errors are clustered at the store level. }{ }^{*}, * * \text { denote significance at the } 10 \% \text { and } \\
5 \% \text { levels, respectively. }\end{array}$} \\
\hline
\end{tabular}


Table 7. Heterogeneity in the Effect of Manager Bias on Work Performance

Dependent Variable: Articles Scanned per Minute

\section{Minority Worker $x$}

Manager Bias

Manager Bias
A. Time During Contract

\begin{tabular}{cc} 
Early Weeks & Late Weeks \\
\hline-0.200 & $-0.422^{* *}$ \\
$(0.141)$ & $(0.160)$
\end{tabular}

0.051

(0.123)

$\begin{array}{ll}2,404 & 1,197 \\ 17.88 & 19.82 \\ 0.249 & 0.249 \\ 0.001 & 0.004\end{array}$

B. Fraction ZUS in the Store

\begin{tabular}{cc} 
Below Median & Above Median \\
\hline$-0.477^{* *}$ & -0.002 \\
$(0.203)$ & $(0.112)$ \\
& \\
$0.267^{* *}$ & -0.102 \\
$(0.099)$ & $(0.168)$ \\
& \\
1,864 & 1,340 \\
18.64 & 18.39 \\
0.037 & 0.037 \\
0.003 & 0.001
\end{tabular}

Note: Each regression shows the result of regressing the dependent variable on the interaction of the worker's minority status and the manager's IAT score (in standard deviation terms), controlling for the manager's IAT score and worker fixed effects. The dependent variable is the number of articles per minute scanned. Observations in the first column are limited to days for which we have the early weeks (weeks 3 to 8 ) of the contract, while observations in the second column are limited to days for which we have the late weeks (weeks 18 to 23) of the contract. Observations in the third column are limited to stores in which managers reported relatively few workers from ZUS (below the median in our sample), while the final column includes the remaining stores.

Observations are worker-days and standard errors are clustered at the store level. ${ }^{* *}$ denotes significance at the $5 \%$ level. 


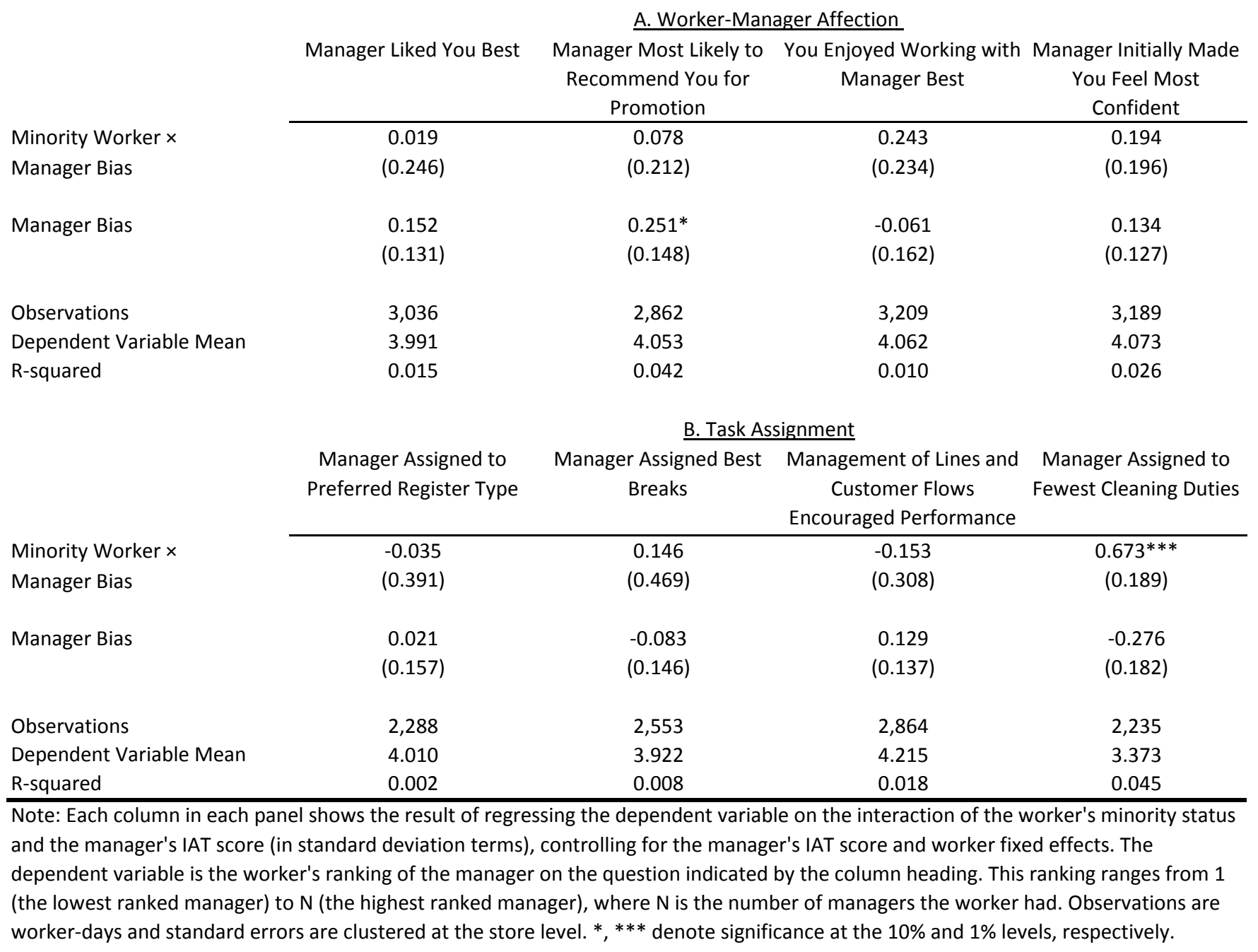




\begin{tabular}{|c|c|c|c|c|}
\hline \multirow{3}{*}{$\begin{array}{l}\text { Remembers Manager } \\
\text { (Indicator) }\end{array}$} & \multicolumn{4}{|c|}{ Panel A. Effect of Worker-Manager Interaction on Performance } \\
\hline & $1.510^{* *}$ & & $1.587^{* *}$ & $2.053 * * *$ \\
\hline & $(0.635)$ & & $(0.630)$ & $(0.744)$ \\
\hline Fraction of Time Scheduled & & -1.172 & 1.724 & 4.021 \\
\hline with Manager & & $(1.352)$ & $(3.638)$ & $(3.828)$ \\
\hline (Fraction of Time Scheduled & & & -4.454 & -6.603 \\
\hline with Manager) ${ }^{2}$ & & & $(4.886)$ & $(5.407)$ \\
\hline Individual F.E.'s & Yes & Yes & Yes & Yes \\
\hline Manager F.E.'s & No & No & No & Yes \\
\hline Observations & 1,885 & 1,885 & 1,885 & 1,885 \\
\hline Dependent Variable Mean & 18.42 & 18.42 & 18.42 & 18.42 \\
\hline \multirow[t]{4}{*}{ R-squared } & 0.008 & 0.001 & 0.010 & 0.095 \\
\hline & \multicolumn{4}{|c|}{ Panel B. Minority Status, Manager Bias, and Worker-Manager Interaction } \\
\hline & $\begin{array}{c}\text { Dependent Variable: } \\
\text { Remembers Manager } \\
\text { (Indicator) }\end{array}$ & & Dependent Varia & es Scanned per Minute \\
\hline & All Days & & All Days & $\begin{array}{l}\text { Days where Worker } \\
\text { Remembers Manager }\end{array}$ \\
\hline Minority Worker $x$ & $-0.0152 *$ & & $-0.415^{*}$ & -0.311 \\
\hline Manager Bias & $(0.0086)$ & & $(0.209)$ & $(0.314)$ \\
\hline Manager Bias & $\begin{array}{l}0.019 *^{*} \\
(0.0097)\end{array}$ & & $\begin{array}{l}0.271^{* *} \\
(0.114)\end{array}$ & $\begin{array}{l}0.203 * * \\
(0.095)\end{array}$ \\
\hline $\begin{array}{l}\text { Fraction of Time Scheduled } \\
\text { with Manager }\end{array}$ & $\begin{array}{l}0.6362^{*} \\
(0.3351)\end{array}$ & & $\begin{array}{l}-1.932 \\
(4.159)\end{array}$ & $\begin{array}{l}-5.115 \\
(4.161)\end{array}$ \\
\hline (Fraction of Time Scheduled & -0.5605 & & 1.017 & 4.114 \\
\hline with Manager) ${ }^{2}$ & & & $(6.270)$ & $(5.757)$ \\
\hline Individual F.E.'s & Yes & & Yes & Yes \\
\hline Observations & 3,958 & & 1,584 & 1,317 \\
\hline Dependent Variable Mean & 0.932 & & 18.52 & 18.66 \\
\hline R-squared & 0.017 & & 0.006 & 0.005 \\
\hline
\end{tabular}

Note: Each regression in Panel A shows the results of regressing articles scanned per minute on the variables listed in the left-most column, controlling for worker fixed effects. Remembers Manager is an indicator for the worker reporting in the worker survey that she remembered the manager she was scheduled to work with that day. Fraction of Time Scheduled with Manager is a number between 0 and 1. It is the fraction of the worker's time in the administrative data that she was scheduled to work with the given manager, averaged over all working days. The first column of Panel B regresses an indicator for whether the worker remembered the manager on the interaction of the worker's minority status and the manager's IAT score (in standard deviation terms), controlling for the manager's IAT score, the fraction of time in the administrative data the worker spent with the manager, this fraction squared, and worker fixed effects. The next column in the panel regresses articles per minute scanned on these same variables. The final column in the panel replicates the previous column, but eliminates days where the worker did not remember the manager. Throughout, observations are worker-days and standard errors are clustered at the store level. *,**,*** denote significance at the $10 \%, 5 \%$, and $1 \%$ levels respectively. 
Table 10. Comparison of Minority and Non-Minority Performance

\begin{tabular}{|c|c|c|c|c|c|}
\hline & $\begin{array}{l}\text { Absence } \\
\text { Indicator }\end{array}$ & $\begin{array}{l}\text { Minutes Worked in } \\
\text { Excess of Schedule }\end{array}$ & $\begin{array}{l}\text { Articles Scanned } \\
\text { per Minute }\end{array}$ & $\begin{array}{l}\text { Inter-Customer Time } \\
\text { (Seconds) }\end{array}$ & $\begin{array}{c}\text { Estimated } \\
\text { Customers Served } \\
\text { per Day }\end{array}$ \\
\hline & \multicolumn{5}{|c|}{ A. All Days } \\
\hline \multirow[t]{2}{*}{ Minority Worker } & -0.0041 & 0.522 & 0.282 & 0.504 & 2.80 \\
\hline & $(0.0072)$ & $(2.213)$ & $(0.329)$ & $(0.719)$ & $(2.02)$ \\
\hline Non-Minority Mean & 0.0187 & -1.186 & 18.55 & 28.21 & 162 \\
\hline Observations & 4,371 & 4,163 & 3,601 & 3,287 & 3,086 \\
\hline \multirow[t]{2}{*}{ Store F.E.'s } & Yes & Yes & Yes & Yes & Yes \\
\hline & \multicolumn{5}{|c|}{ B. Days with Unbiased Managers } \\
\hline \multirow[t]{2}{*}{ Minority Worker } & $-0.0127^{*}$ & 2.572 & $0.745 * *$ & $-2.075^{*}$ & $13.94 * *$ \\
\hline & $(0.0067)$ & $(2.331)$ & $(0.323)$ & $(1.113)$ & $(4.84)$ \\
\hline Non-Minority Mean & 0.0267 & -4.268 & 18.65 & 26.59 & 162 \\
\hline Observations & 482 & 444 & 367 & 330 & 301 \\
\hline \multirow[t]{2}{*}{ Store F.E.'s } & Yes & Yes & Yes & Yes & Yes \\
\hline & \multicolumn{5}{|c|}{$\underline{\text { C. Days with Biased Managers }}$} \\
\hline \multirow[t]{2}{*}{ Minority Worker } & -0.0047 & 0.271 & 0.006 & 0.936 & 2.21 \\
\hline & $(0.0094)$ & $(2.872)$ & $(0.383)$ & $(0.935)$ & $(2.68)$ \\
\hline Non-Minority Mean & 0.0194 & -1.106 & 18.65 & 27.94 & 162 \\
\hline Observations & 3,474 & 3,319 & 2,832 & 2,555 & 2,395 \\
\hline \multirow[t]{2}{*}{ Store F.E.'s } & Yes & Yes & Yes & Yes & Yes \\
\hline & \multicolumn{5}{|c|}{ D. All Other Days } \\
\hline \multirow[t]{2}{*}{ Minority Worker } & 0.0026 & 0.379 & $1.292^{* *}$ & 0.178 & -0.25 \\
\hline & $(0.0027)$ & $(1.625)$ & $(0.325)$ & $(0.186)$ & $(2.05)$ \\
\hline Non-Minority Mean & 0.0036 & 0.928 & 17.69 & 31.88 & 156 \\
\hline Observations & 445 & 429 & 422 & 421 & 410 \\
\hline Store F.E.'s & Yes & Yes & Yes & Yes & Yes \\
\hline \multicolumn{6}{|c|}{$\begin{array}{l}\text { Note: Each column in each panel shows the result of a separate regression of the dependent variable indicated by the column on } \\
\text { an indicator for the worker being a minority, controlling for store fixed effects. Estimated Customers Served per Day is calculated } \\
\text { under the assumption that customers average } 25 \text { items. Standard errors are clustered at the store level. Days with Unbiased } \\
\text { Managers are days where the worker spent at least } 50 \% \text { of the day with managers with a raw (unscaled) IAT score between }-0.15 \\
\text { and } 0.15 \text {. Days with Biased Managers are days where the worker spent more than } 50 \% \text { of the day with managers whose raw IAT } \\
\text { score exceeds } 0.15 \text {. Days where a worker spent more than } 50 \% \text { of her time with managers biased in favor of minorities (managers } \\
\text { with raw IAT scores below }-0.15 \text { ) and days where a worker did not spend more than } 50 \% \text { of her time with managers in any bias } \\
\text { category are included in Panel D as "All Other Days." } *, * * \text { denote significance at the } 10 \% \text { and } 5 \% \text { levels, respectively. }\end{array}$} \\
\hline
\end{tabular}


Table 11. Effect of Manager Bias on Performance in Rest of the Week Dependent Variable: Average Performance in Rest of the Week

\begin{tabular}{lcccc} 
& $\begin{array}{c}\text { Absence } \\
\text { Indicator }\end{array}$ & $\begin{array}{c}\text { Minutes Worked } \\
\text { in Excess of } \\
\text { Schedule }\end{array}$ & $\begin{array}{c}\text { Articles } \\
\text { Scanned per } \\
\text { Minute }\end{array}$ & $\begin{array}{c}\text { Inter-Customer } \\
\text { Time (Seconds) }\end{array}$ \\
\cline { 2 - 5 } $\begin{array}{l}\text { Minority Worker } x \\
\text { Manager Bias }\end{array}$ & 0.0023 & -0.628 & $-0.099^{* *}$ & -0.336 \\
& $(0.0020)$ & $(0.940)$ & $(0.041)$ & $(0.274)$ \\
Manager Bias & -0.0029 & $1.185^{*}$ & 0.063 & -0.030 \\
& $(0.0017)$ & $(0.638)$ & $(0.046)$ & $(0.203)$ \\
Observations & & & & \\
Dependent Variable Mean & 4,271 & 4,174 & 3,935 & 3,610 \\
R-squared & 0.0153 & -0.053 & 18.43 & 29.04 \\
\hline
\end{tabular}

Notes: Each column shows the result of regressing the workers' average performance in the rest of the week on the interaction of the worker's minority status and the manager's IAT score (in standard deviation terms) on a given day. Regressions control for the manager's IAT score on that day and worker fixed effects. We also control for the average manager IAT score in the rest of the week and this score interacted with the worker's minority status. Standard errors are clustered at the store level. ${ }^{* *}$ denotes significance at the $5 \%$ level. 


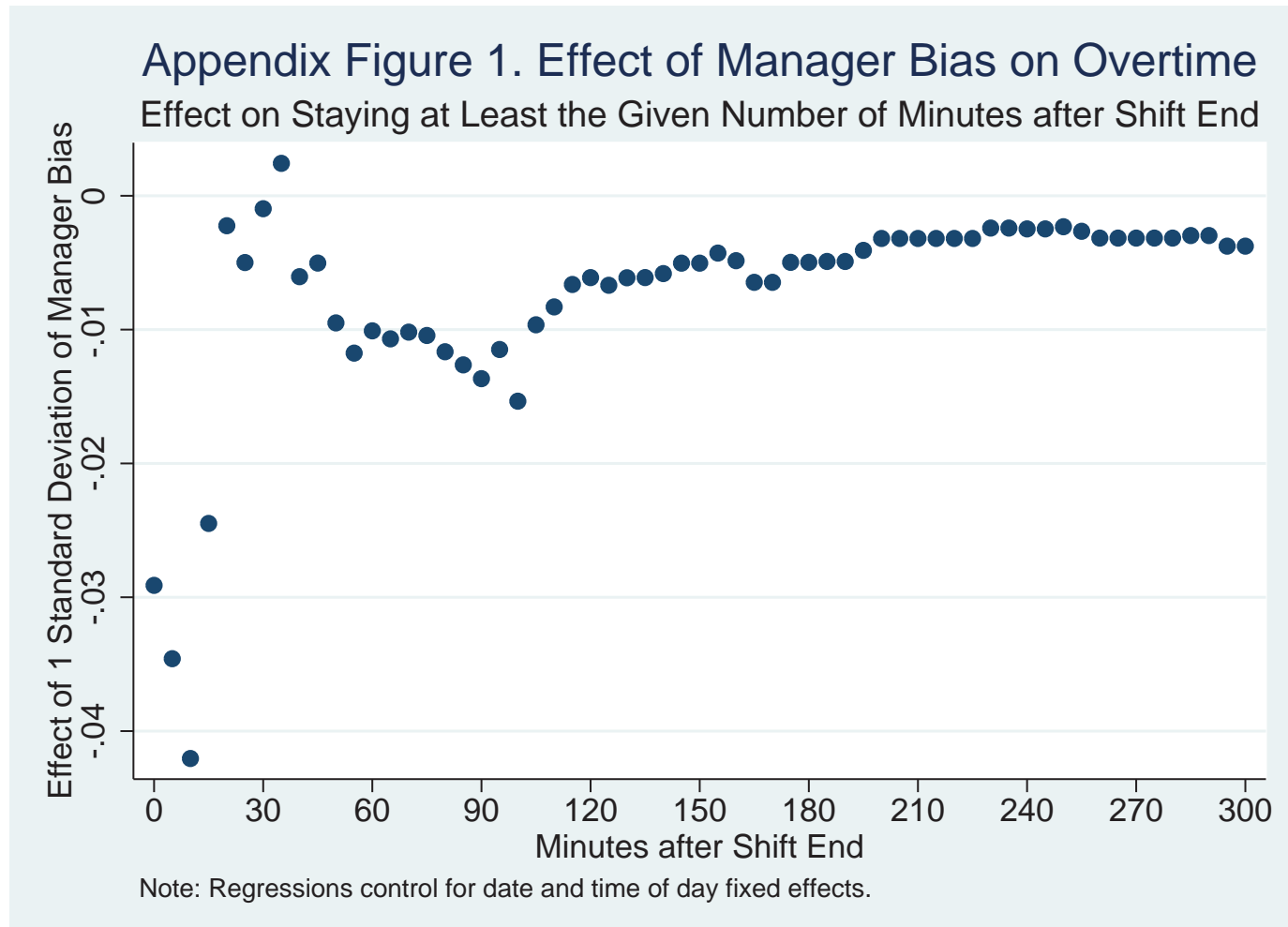


Appendix Table 1. Characteristics of Respondents and Non-Respondents to the CP Survey

\begin{tabular}{|c|c|c|c|c|c|c|c|c|c|}
\hline & \multicolumn{3}{|c|}{ All Workers } & \multicolumn{3}{|c|}{ Minority Workers } & \multicolumn{3}{|c|}{ Majority Workers } \\
\hline & Respondents & $\begin{array}{c}\text { Non- } \\
\text { Respondents }\end{array}$ & $\begin{array}{l}p \text {-value of } \\
\text { Difference }\end{array}$ & Respondents & $\begin{array}{c}\text { Non- } \\
\text { Respondents }\end{array}$ & $\begin{array}{l}\mathrm{p} \text {-value of } \\
\text { Difference }\end{array}$ & Respondents & $\begin{array}{c}\text { Non- } \\
\text { Respondents }\end{array}$ & $\begin{array}{l}p \text {-value of } \\
\text { Difference }\end{array}$ \\
\hline Male & $7.7 \%$ & $8.1 \%$ & 0.855 & $6.7 \%$ & $6.8 \%$ & 0.994 & $8.1 \%$ & $9.0 \%$ & 0.743 \\
\hline Absence Rate & 0.018 & 0.028 & 0.423 & 0.016 & 0.006 & 0.364 & 0.016 & 0.037 & 0.235 \\
\hline Minutes Worked in Excess of Schedule & 2.59 & -2.51 & 0.064 & 2.92 & 1.29 & 0.765 & 2.51 & -4.58 & 0.031 \\
\hline Articles Scanned per Minute & 18.57 & 18.43 & 0.699 & 18.84 & 18.20 & 0.298 & 18.51 & 18.56 & 0.919 \\
\hline Inter-Customer Time (Seconds) & 28.51 & 29.50 & 0.420 & 27.94 & 31.24 & 0.130 & 28.65 & 28.52 & 0.933 \\
\hline Payment Time (Seconds) & 50.51 & 50.73 & 0.768 & 51.83 & 52.13 & 0.823 & 50.17 & 50.02 & 0.868 \\
\hline Paris Region & $42 \%$ & $49 \%$ & 0.095 & $63 \%$ & $59 \%$ & 0.585 & $33 \%$ & $41 \%$ & 0.103 \\
\hline Municipality has Less than 25,000 Residents & $33 \%$ & $29 \%$ & 0.330 & $28 \%$ & $24 \%$ & 0.544 & $35 \%$ & $33 \%$ & 0.639 \\
\hline Municipality has 25,000 to 75,000 Residents & $49 \%$ & $52 \%$ & 0.435 & $54 \%$ & $54 \%$ & 0.984 & $47 \%$ & $50 \%$ & 0.457 \\
\hline Municipality has More than 75,000 Residents & $18 \%$ & $19 \%$ & 0.877 & $18 \%$ & $21 \%$ & 0.524 & $19 \%$ & $17 \%$ & 0.696 \\
\hline
\end{tabular}

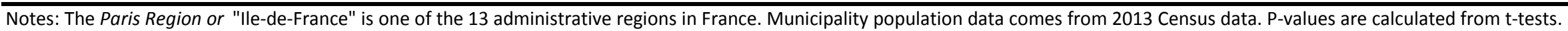


Appendix Table 2. Correlates of Manager IAT Scores

Dependent Variable: Standardized Manager IAT Score

\begin{tabular}{|c|c|c|c|c|c|c|c|c|}
\hline \multirow[t]{2}{*}{ Minority } & -0.441 & & & & & & -0.364 & -0.135 \\
\hline & $(0.345)$ & & & & & & $(0.388)$ & $(0.445)$ \\
\hline \multirow[t]{2}{*}{ Male } & & -0.078 & & & & & 0.109 & 0.092 \\
\hline & & $(0.448)$ & & & & & (0.617) & (0.675) \\
\hline \multirow[t]{2}{*}{ Age } & & & 0.008 & & & & 0.008 & 0.003 \\
\hline & & & $(0.010)$ & & & & $(0.012)$ & $(0.018)$ \\
\hline \multirow[t]{2}{*}{ Level 4 (High Position) } & & & & 0.019 & & & -0.093 & 0.329 \\
\hline & & & & $(0.266)$ & & & $(0.290)$ & $(0.366)$ \\
\hline \multirow[t]{2}{*}{ Fraction ZUS in Store } & & & & & -0.005 & & -0.005 & \\
\hline & & & & & $(0.004)$ & & $(0.007)$ & \\
\hline \multirow[t]{2}{*}{ Far Right Vote Share } & & & & & & 0.005 & -0.006 & \\
\hline & & & & & & $(0.016)$ & $(0.016)$ & \\
\hline Observations & 119 & 119 & 119 & 119 & 110 & 119 & 110 & 119 \\
\hline R-squared & 0.014 & 0.000 & 0.005 & 0.000 & 0.003 & 0.001 & 0.021 & 0.269 \\
\hline Dependent Variable Mean & 1.346 & 1.346 & 1.346 & 1.346 & 1.410 & 1.346 & 1.410 & 1.346 \\
\hline Store F.E.'s & No & No & No & No & No & No & No & Yes \\
\hline
\end{tabular}

Note: Each column shows the results of regressing a manager's (standardized) IAT score on her characteristics. Level 4 managers have a higher position in the store than the remaining managers. Manager age is reported as of January 1, 2012. Fraction ZUS in Store is the fraction of workers that come from "sensitive urban zones," zones with high concentrations of immigrants and first generation citizens, and is measured on a scale of 1 to 100. Far Right Vote Share is the share of votes received by the Front National Party in the first round of the 2012 presidential election. This data comes from the French Ministry of the Interior. Standard errors are clustered at the store level. 
Appendix Table 3. Exogeneity of Scheduled Shifts

Robustness to Alternative Specifications

\begin{tabular}{|c|c|c|c|c|c|c|c|c|c|c|}
\hline & Manager Bias & $\begin{array}{l}\text { Minority } \\
\text { Manager }\end{array}$ & $\begin{array}{c}\text { Male } \\
\text { Manager }\end{array}$ & $\begin{array}{l}\text { Level } 4 \\
\text { Manager }\end{array}$ & $\begin{array}{c}\text { Total } \\
\text { Managers }\end{array}$ & $\begin{array}{l}\text { Articles per } \\
\text { Minute in Other } \\
\text { Stores on that } \\
\text { Date }\end{array}$ & $\begin{array}{l}\text { Shift Includes } \\
\text { Early Morning }\end{array}$ & $\begin{array}{l}\text { Shift Includes } \\
\text { Late Evening }\end{array}$ & $\begin{array}{l}\text { Total } \\
\text { Hours }\end{array}$ & Split Shift \\
\hline \multicolumn{11}{|c|}{ A. Minority Workers, Including Observations with No Manager IAT } \\
\hline Minority Worker & $\begin{array}{c}0.005 \\
(0.022)\end{array}$ & $\begin{array}{l}-0.009 \\
(0.007)\end{array}$ & $\begin{array}{l}-0.020 \\
(0.014)\end{array}$ & $\begin{array}{l}-0.008 \\
(0.010)\end{array}$ & $\begin{array}{l}-0.127 \\
(0.115)\end{array}$ & $\begin{array}{c}0.043 \\
(0.072)\end{array}$ & $\begin{array}{c}0.008 \\
(0.013)\end{array}$ & $\begin{array}{c}0.014 \\
(0.012)\end{array}$ & $\begin{array}{c}0.034 \\
(0.029)\end{array}$ & $\begin{array}{l}-0.001 \\
(0.010)\end{array}$ \\
\hline $\begin{array}{l}\text { Observations } \\
\text { Dependent }\end{array}$ & 4,371 & 5,099 & 5,099 & 5,099 & 5,099 & 4,945 & 5,099 & 5,099 & 5,094 & 5,099 \\
\hline Variable Mean & 1.13 & 0.051 & 0.116 & 0.156 & 2.44 & 18.28 & 0.141 & 0.581 & 7.20 & 0.461 \\
\hline Store F.E.'s & Yes & Yes & Yes & Yes & Yes & Yes & Yes & Yes & Yes & Yes \\
\hline \multicolumn{11}{|c|}{ B. Minority Workers and Manager Bias, with Worker Fixed Effects } \\
\hline Minority Worker $x$ & & 0.034 & 0.024 & 0.031 & -0.059 & -0.057 & -0.013 & 0.016 & -0.077 & -0.027 \\
\hline Manager Bias & & $(0.024)$ & $(0.024)$ & $(0.037)$ & $(0.050)$ & $(0.064)$ & $(0.021)$ & $(0.025)$ & $(0.110)$ & $(0.031)$ \\
\hline Manager Bias & & $\begin{array}{l}-0.040 \\
(0.026)\end{array}$ & $\begin{array}{c}0.007 \\
(0.023)\end{array}$ & $\begin{array}{c}0.030 \\
(0.039)\end{array}$ & $\begin{array}{c}0.019 \\
(0.052)\end{array}$ & $\begin{array}{c}0.065 \\
(0.055)\end{array}$ & $\begin{array}{c}0.006 \\
(0.013)\end{array}$ & $\begin{array}{l}-0.015 \\
(0.023)\end{array}$ & $\begin{array}{l}-0.045 \\
(0.067)\end{array}$ & $\begin{array}{l}-0.013 \\
(0.024)\end{array}$ \\
\hline Observations & & 4,371 & 4,371 & 4,371 & 4,371 & 4,238 & 4,371 & 4,371 & 4,368 & 4,371 \\
\hline Dependent Variabl & Mean & 0.060 & 0.114 & 0.171 & 2.74 & 18.23 & 0.141 & 0.580 & 7.22 & 0.465 \\
\hline Individual F.E.'s & & Yes & Yes & Yes & Yes & Yes & Yes & Yes & Yes & Yes \\
\hline
\end{tabular}




\begin{tabular}{lcc}
\hline & $\begin{array}{c}\text { Scheduled to Work at } \\
\text { Same Time }\end{array}$ & $\begin{array}{c}\text { Minutes Scheduled } \\
\text { to Work Together }\end{array}$ \\
\cline { 2 - 3 } Minority-Minority Pair & -0.015 & -6.10 \\
& $(0.036)$ & $(11.66)$ \\
Minority-Majority Pair & -0.014 & -5.73 \\
& $(0.022)$ & $(7.26)$ \\
Store F.E.'s & & \\
Observations & Yes & Yes \\
Mean Dep. Var. & 15,791 & 15,791 \\
\hline
\end{tabular}

Note: The table shows the result of regressing an indicator for whether two CPs in the same store were scheduled to work together on a given day (Column 1) and the number of minutes they were scheduled to work together on a given day (Column 2) on an indicator for both CPs being minorities and an indicator for one worker being a minority and the other being a majority. The omitted category is both workers being majorities. Observations are CP pairdays. Store fixed effects are included and standard errors are clustered at the store level. 


\begin{tabular}{|c|c|c|c|c|}
\hline Minority Worker $x$ & -0.188 & -0.091 & -0.064 & -0.011 \\
\hline Manager Bias & $(0.457)$ & $(0.413)$ & $(0.361)$ & $(0.341)$ \\
\hline Manager Bias & $\begin{array}{c}0.046 \\
(0.314)\end{array}$ & $\begin{array}{c}0.049 \\
(0.281)\end{array}$ & $\begin{array}{c}-0.453 \\
(0.325)\end{array}$ & $\begin{array}{c}-0.506 * \\
(0.290)\end{array}$ \\
\hline Observations & 3,108 & 3,108 & 3,108 & 3,108 \\
\hline Dependent Variable Mean & 50.77 & 50.77 & 50.77 & 50.77 \\
\hline R-squared & 0.000 & 0.039 & 0.159 & 0.159 \\
\hline Individual F.E.'s & Yes & Yes & Yes & Yes \\
\hline Day of the Week F.E.'s & No & Yes & No & No \\
\hline Morning/Evening F.E.'s & No & Yes & Yes & Yes \\
\hline Date F.E.'s & No & No & Yes & Yes \\
\hline Manager Minority Variables & No & No & No & Yes \\
\hline \multicolumn{5}{|c|}{$\begin{array}{l}\text { Note: Each regression shows the result of regressing the dependent variable on the interaction } \\
\text { of the worker's minority status and the manager's IAT score (in standard deviation terms), } \\
\text { controlling for the manager's IAT score and worker fixed effects. The first column includes no } \\
\text { controls. The second column adds day of the week fixed effects, an indicator for the shift } \\
\text { starting at } 9 \text { am or earlier, and an indicator for the shift ending at } 8 \mathrm{pm} \text { or later. The third } \\
\text { column includes date fixed effects and drops the day of the week fixed effects. The last column } \\
\text { adds a dummy for the manager being a minority and the interaction of the worker's and the } \\
\text { manager's minority status. Observations are worker-days and standard errors are clustered at } \\
\text { the store level. * denotes significance at the } 10 \% \text { level. }\end{array}$} \\
\hline
\end{tabular}


Appendix Table 6. Effect of Manager Bias on Time at Work and Work Performance Including Controls for Other Manager Characteristics

\begin{tabular}{|c|c|c|c|c|}
\hline & $\begin{array}{l}\text { Absence } \\
\text { Indicator }\end{array}$ & $\begin{array}{l}\text { Minutes Worked in } \\
\text { Excess of Schedule }\end{array}$ & $\begin{array}{c}\text { Articles Scanned } \\
\text { per Minute }\end{array}$ & $\begin{array}{l}\text { Inter-Customer } \\
\text { Time (Seconds) }\end{array}$ \\
\hline Minority Worker $\times$ & $0.0139 * *$ & -2.101 & $-0.277 * *$ & $1.523 * *$ \\
\hline Manager Bias & $(0.0058)$ & $(1.639)$ & $(0.123)$ & $(0.743)$ \\
\hline Manager Bias & $\begin{array}{l}-0.0064 \\
(0.0043)\end{array}$ & $\begin{array}{c}1.007 \\
(1.082)\end{array}$ & $\begin{array}{l}0.1011 \\
(0.078)\end{array}$ & $\begin{array}{l}-0.269 \\
(0.428)\end{array}$ \\
\hline Observations & 4,371 & 4,163 & 3,601 & 3,287 \\
\hline Dependent Variable Mean & 0.0162 & -0.068 & 18.53 & 28.70 \\
\hline R-squared & 0.088 & 0.131 & 0.196 & 0.241 \\
\hline \multicolumn{5}{|c|}{$\begin{array}{l}\text { Note: The regressions in this table replicate the regressions in the final columns of Table } 4 \mathrm{~A}, 4 \mathrm{~B}, 6 \mathrm{~A} \text {, and } 6 \mathrm{~B} \\
\text { respectively, adding additional control variables. The regressions include individual and date fixed effects, } \\
\text { dummies for early morning and late evening shifts, an indicator for manager minority status, and the } \\
\text { interaction of the worker's and manager's minority status. The regressions also include a dummy for the } \\
\text { manager having a Level } 4 \text { position, a dummy for the manager being male, manager age as of January } 1 \text {, } \\
2012 \text {, and the interaction of each of these variables with the worker's minority status. }{ }^{* *} \text { denotes } \\
\text { significance at the } 5 \% \text { level. }\end{array}$} \\
\hline
\end{tabular}


Appendix Table 7. Effect of Manager Bias on Time at Work and Work Performance Different Definitions of Minority Status

\begin{tabular}{|c|c|c|c|c|}
\hline & $\begin{array}{l}\text { Absence } \\
\text { Indicator }\end{array}$ & $\begin{array}{l}\text { Minutes Worked in } \\
\text { Excess of Schedule }\end{array}$ & $\begin{array}{c}\text { Articles Scanned } \\
\text { per Minute } \\
\end{array}$ & $\begin{array}{l}\text { Inter-Customer } \\
\text { Time (Seconds) } \\
\end{array}$ \\
\hline & \multicolumn{4}{|c|}{ A. Minorities as Workers with North African Names } \\
\hline Minority Worker $x$ & $0.0150 * *$ & -2.437 & -0.228 & 1.305 \\
\hline Manager Bias & $(0.0060)$ & $(1.791)$ & $(0.153)$ & $(0.890)$ \\
\hline \multirow[t]{2}{*}{ Manager Bias } & -0.0053 & 1.238 & 0.075 & -0.516 \\
\hline & $(0.0039)$ & $(0.934)$ & $(0.065)$ & $(0.503)$ \\
\hline Observations & 3,994 & 3,795 & 3,277 & 3,012 \\
\hline Dependent Variable Mean & 0.0168 & -0.725 & 18.51 & 28.46 \\
\hline \multirow[t]{2}{*}{ R-squared } & 0.091 & 0.141 & 0.206 & 0.237 \\
\hline & \multicolumn{4}{|c|}{ B. Minorities as Workers with Sub-Saharan African Names } \\
\hline Minority Worker $x$ & $0.0082 *$ & -6.010 & -0.225 & $1.506 *$ \\
\hline Manager Bias & $(0.0044)$ & $(3.786)$ & $(0.138)$ & $(0.854)$ \\
\hline \multirow[t]{2}{*}{ Manager Bias } & -0.0043 & 0.982 & 0.067 & -0.701 \\
\hline & $(0.0038)$ & $(1.001)$ & $(0.062)$ & $(0.545)$ \\
\hline Observations & 3,561 & 3,380 & 2,906 & 2,670 \\
\hline Dependent Variable Mean & 0.0177 & -0.346 & 18.59 & 28.47 \\
\hline \multirow[t]{2}{*}{ R-squared } & 0.100 & 0.131 & 0.217 & 0.249 \\
\hline & \multicolumn{4}{|c|}{ C. Workers of Indeterminate, Mixed, or Other Origin Excluded } \\
\hline Minority Worker $x$ & $0.0116^{* *}$ & $-3.166^{*}$ & $-0.181^{* *}$ & $1.282 *$ \\
\hline Manager Bias & $(0.0053)$ & $(1.755)$ & $(0.076)$ & $(0.627)$ \\
\hline \multirow[t]{2}{*}{ Manager Bias } & -0.0052 & 0.812 & 0.030 & -0.565 \\
\hline & $(0.0045)$ & $(0.984)$ & $(0.064)$ & $(0.465)$ \\
\hline Observations & 4,000 & 3,824 & 3,301 & 3,033 \\
\hline Dependent Variable Mean & 0.0173 & -0.020 & 18.61 & 28.69 \\
\hline R-squared & 0.093 & 0.139 & 0.231 & 0.235 \\
\hline \multicolumn{5}{|c|}{$\begin{array}{l}\text { Note: The regressions in this table replicate the regressions in the final columns of Table 4A, 4B, 6A, and 6B, } \\
\text { respectively. Regressions in Panel A define as minorities workers with a first or last name of North African } \\
\text { origin. Remaining workers with a Sub-Saharan African first or last name are eliminated. Regressions in Panel } \\
\text { B define as minorities workers with a first or last name of Sub-Saharan African origin, eliminating other } \\
\text { workers with North African names. Regressions in Panel C use the original definition of minority (a first or } \\
\text { last name of Sub-Saharan or North African origin), but eliminate workers with names of indeterminate, } \\
\text { mixed, or other origin. } *, * * \text { denote significance at the } 10 \% \text { and } 5 \% \text { levels, respectively. }\end{array}$} \\
\hline
\end{tabular}


Appendix Table 8. Effect of Manager Bias on Time at Work and Work Performance Controlling for Within-Store Shift Effects

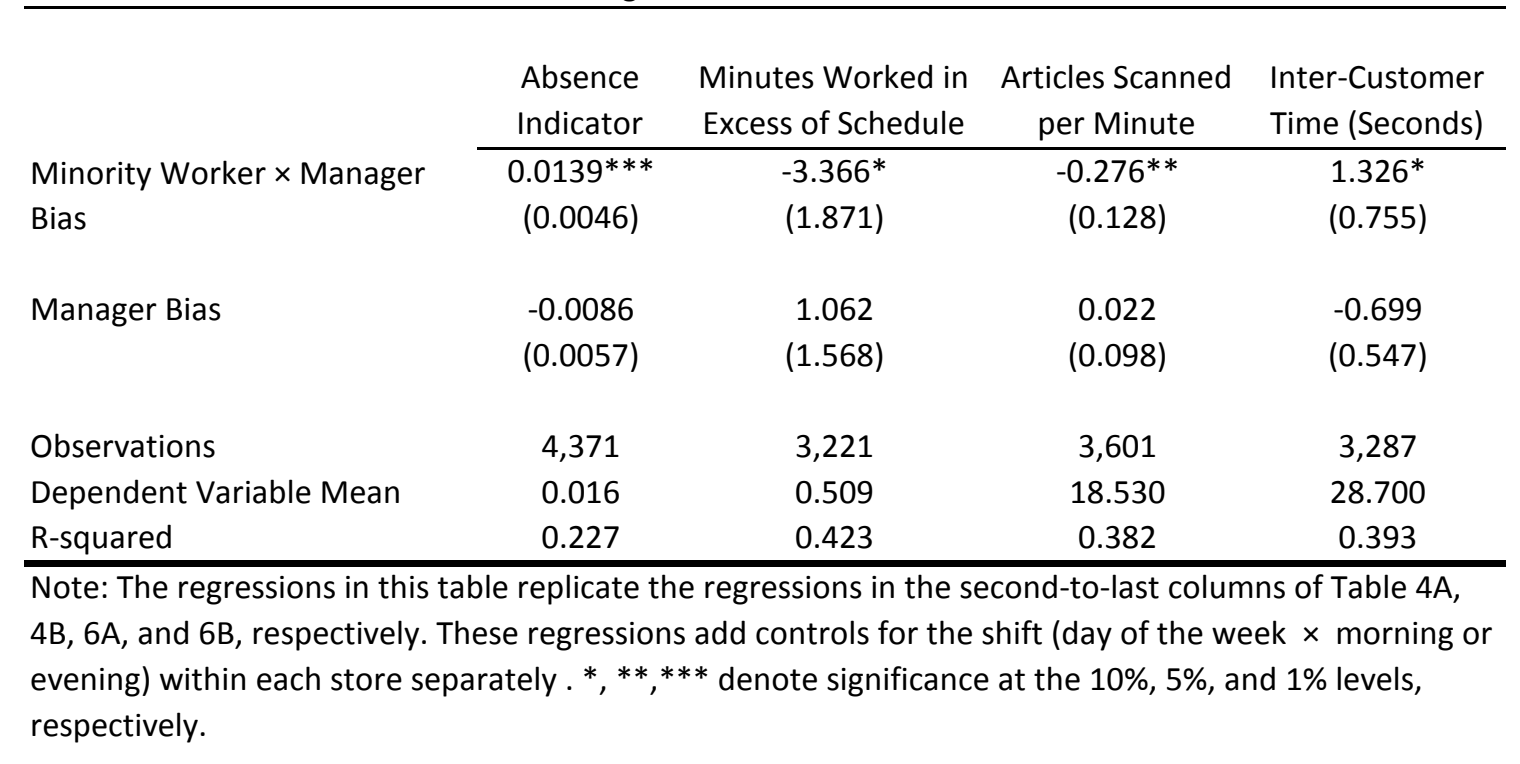




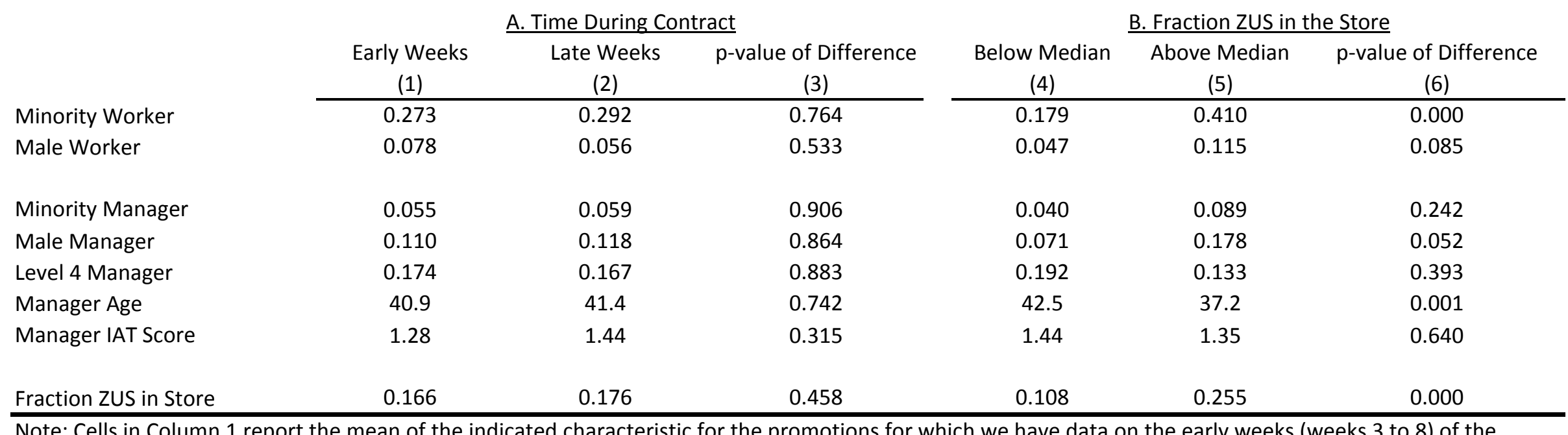

Note: Cells in Column 1 report the mean of the indicated characteristic for the promotions for which we have data on the early weeks (weeks 3 to 8 ) of the contract. Cells in Column 2 report the mean of the indicated characteristic for the promotions for which we have data on the late weeks (weeks 18 to 23 ) of the contract. Column 3 presents the p-values from a test of the hypothesis that the means of both samples are the same. Cells in Column 4 report the mean of the indicated characteristic for stores in which managers report they managed relatively few workers from ZUS (below the median in our sample), while cells in Column 5 report means for the remaining stores. Column 6 reports $p$-values from a test of the hypothesis that the means of both samples are the same. 


\begin{tabular}{|c|c|c|c|c|}
\hline & & Level of Time & gregation & \\
\hline & One Day & Two Working Days & $\begin{array}{c}\text { One Calendar } \\
\text { Week }\end{array}$ & $\begin{array}{c}\text { Two Calendar } \\
\text { Weeks }\end{array}$ \\
\hline & & A. Abse & & \\
\hline Minority Worker $\times$ & $0.0098 * *$ & 0.0021 & 0.0091 & 0.0115 \\
\hline Manager Bias & $(0.0039)$ & $(0.0043)$ & $(0.0106)$ & $(0.0245)$ \\
\hline Manager Bias & -0.0021 & 0.0008 & -0.0051 & -0.0047 \\
\hline & $(0.0031)$ & $(0.0037)$ & $(0.0098)$ & $(0.0223)$ \\
\hline Observations & 4,371 & 2,386 & 1,209 & 651 \\
\hline Dependent Variable Mean & 0.0162 & 0.0176 & 0.0226 & 0.0252 \\
\hline R-squared & 0.0005 & 0.0001 & 0.0004 & 0.0004 \\
\hline & & B. Articles Scanne & per Minute & \\
\hline Minority Worker $\times$ & $-0.276 * *$ & $-0.305^{* * *}$ & $-0.508^{* * *}$ & -0.604 \\
\hline Manager Bias & $(0.109)$ & $(0.092)$ & $(0.180)$ & $(0.361)$ \\
\hline Manager Bias & $0.140 *$ & $0.221^{*}$ & $0.400 * *$ & $0.716 * *$ \\
\hline & $(0.083)$ & $(0.124)$ & $(0.159)$ & $(0.341)$ \\
\hline Observations & 3,601 & 2,149 & 1,111 & 605 \\
\hline Dependent Variable Mean & 18.53 & 18.46 & 18.59 & 18.60 \\
\hline R-squared & 0.0015 & 0.0034 & 0.0130 & 0.0316 \\
\hline Individual F.E.'s & Yes & Yes & Yes & Yes \\
\hline $\begin{array}{l}\text { Note: Each column in each } \\
\text { interaction of the worker's } \\
\text { controlling for the manager } \\
\text { column reproduces results } \\
\text { for the worker being absent } \\
\text { remaining columns aggrega } \\
\text { bias and the dependent var } \\
\text { absence indicator is no long } \\
\text { span is two consecutive wo } \\
\text { include an odd number of d } \\
\text { period.) In the third column } \\
\text { column the time span is two } \\
\text { denote significance at the } 1\end{array}$ & $\begin{array}{l}\text { shows the } r \\
\text { ity status ar } \\
\text { score and } \mathrm{r} \\
\text { ables } 4 \mathrm{~A} \text { ar } \\
\text { l A) and th } \\
\text { ervations o } \\
\text { are averag } \\
\text { indicator, b } \\
\text { days, so tha } \\
r \text { a given w } \\
\text { ime span is } \\
\text { dar weeks. } \\
\% \text {, and } 1 \% \text { I }\end{array}$ & $\begin{array}{l}\text { ts of regressing the d } \\
\text { le manager's IAT scor } \\
\text { er fixed effects. No o } \\
\text { A, respectively. The c } \\
\text { mber of articles per r } \\
\text { longer time periods. } \\
\text { y worker) over the } r \\
\text { rate between } 0 \text { and } \\
\text { servations are worke } \\
r \text {, one observation fo } \\
\text { lendar week (typical } \\
\text { ndard errors are clus } \\
s, \text { respectively. }\end{array}$ & $\begin{array}{l}\text { pendent variabl } \\
\text { (in standard de } \\
\text { ler controls are } \\
\text { pendent variab } \\
\text { inute scanned ( } \\
\text { these regressio } \\
\text { evant time fram } \\
\text { In the second c } \\
\text { two day periods } \\
\text { the worker is a } \\
\text { four working da } \\
\text { red at the store }\end{array}$ & $\begin{array}{l}\mathrm{n} \text { the } \\
\text { tion terms), } \\
\text { luded. The first } \\
\mathrm{s} \text { an indicator } \\
\text { el B). The } \\
\text { both manager } \\
\text { so that the } \\
\mathrm{mn} \text {, the time } \\
\mathrm{f} \text { the data } \\
\text { rker-one day } \\
\text {, and in the last } \\
\text { vel. } *, * *, * * *\end{array}$ \\
\hline
\end{tabular}

